\title{
Prognostic Analysis of the Tactical Quiet Generator
}

\section{September 2008}

\author{
Prepared by \\ L. M. Hively, Ph.D. \\ Oak Ridge National Laboratory
}




\section{DOCUMENT AVAILABILITY}

Reports produced after January 1, 1996, are generally available free via the U.S. Department of Energy (DOE) Information Bridge:

Web site: http://www.osti.gov/bridge

Reports produced before January 1, 1996, may be purchased by members of the public from the following source:

National Technical Information Service

5285 Port Royal Road

Springfield, VA 22161

Telephone: 703-605-6000 (1-800-553-6847)

TDD: 703-487-4639

Fax: 703-605-6900

E-Mail: info@ntis.fedworld.gov

Web site: http://www.ntis.gov/support/ordernowabout.htm

Reports are available to DOE employees, DOE contractors, Energy Technology Data Exchange (ETDE) representatives, and International Nuclear Information System (INIS) representatives from the following source:

Office of Scientific and Technical Information

P.O. Box 62

Oak Ridge, TN 37831

Telephone: 865-576-8401

Fax: 865-576-5728

E-mail: reports@adonis.osti.gov

Web site: http://www.osti.gov/contact.html

This report was prepared as an account of work sponsored by an agency of the United States Government. Neither the United States government nor any agency thereof, nor any of their employees, makes any warranty, express or implied, or assumes any legal liability or responsibility for the accuracy, completeness, or usefulness of any information, apparatus, product, or process disclosed, or represents that its use would not infringe privately owned rights. Reference herein to any specific commercial product, process, or service by trade name, trademark, manufacturer, or otherwise, does not necessarily constitute or imply its endorsement, recommendation, or favoring by the United States Government or any agency thereof. The views and opinions of authors expressed herein do not necessarily state or reflect those of the United States Government or any agency thereof. 


\section{PROGNOSTIC ANALYSIS OF THE TACTICAL QUIET GENERATOR}

L. M. Hively, Ph.D.

Oak Ridge National Laboratory

Date Published: September 2008

Prepared by

OAK RIDGE NATIONAL LABORATORY

P.O. Box 2008

Oak Ridge, Tennessee 37831-6285

Managed by

UT-Battelle, LLC

for the

U.S. DEPARTMENT OF ENERGY

under contract DE-AC05-00OR22725 

TABLE OF CONTENTS

$\begin{array}{ll}\text { Section Title } & \text { Page }\end{array}$

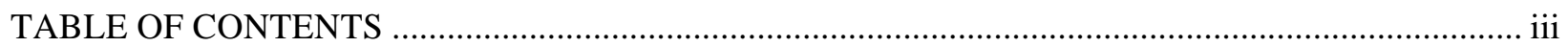

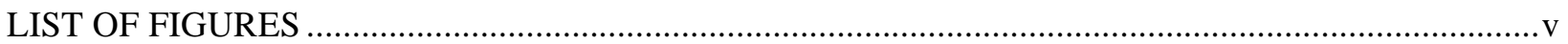

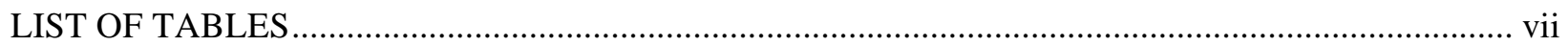

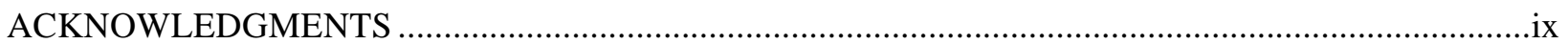

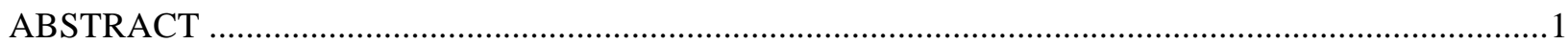

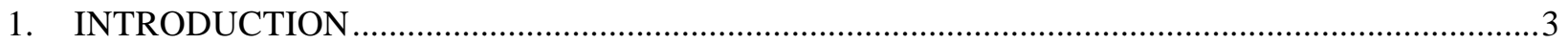

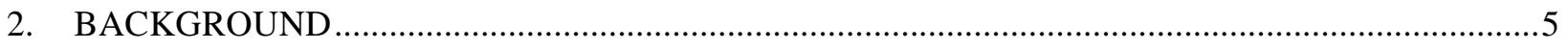

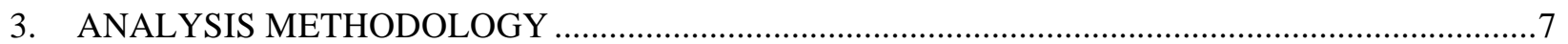

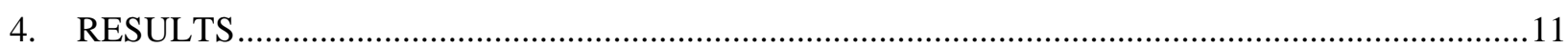

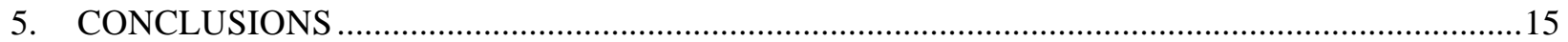

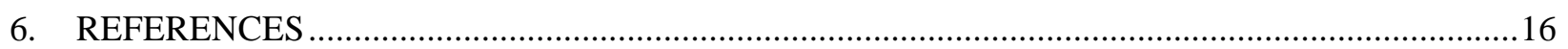





\section{LIST OF FIGURES}

Figure

Page

No table of figures entries found.

In your document, select the words to include in the table of contents, and then in the Formatting Palette under Styles, click a heading style. Repeat for each heading that you want to include, and then insert the table of contents in your document. You can also create a table of contents by clicking the Create with Manual Formatting option and then type the entries manually. 



\section{LIST OF TABLES}

Table

Page

No table of figures entries found.

In your document, select the words to include in the table of contents, and then in the Formatting Palette under Styles, click a heading style. Repeat for each heading that you want to include, and then insert the table of contents in your document. You can also create a table of contents by clicking the Create with Manual Formatting option and then type the entries manually. 



\section{ACKNOWLEDGMENTS}

This work was sponsored by the U.S. Army Research Laboratory (ARL) under work-for-others inter-agency agreement, Proposal \#2374-S714-A1, "Specialized R\&D Support for the RDECOM," Task 3.2 (In Support of Technology Development, Demonstration, and Validation). Oak Ridge National Laboratory is managed for the U.S. Department of Energy by UT-Battelle, LLC, under Contract No. DE-AC05-00OR22725. We thank ARL for providing the data that was analyzed here. 



\begin{abstract}
The U.S. Army needs prognostic analysis of mission-critical equipment to enable condition-based maintenance before failure. ORNL has developed and patented prognostic technology that quantifies condition change from noisy, multi-channel, time-serial data. This report describes an initial application of ORNL's prognostic technology to the Army's Tactical Quiet Generator (TQG), which is designed to operate continuously at $10 \mathrm{~kW}$. Less-than-full power operation causes unburned fuel to accumulate on internal components, thereby degrading operation and eventually leading to failure. The first objective of this work was identification of easily-acquired, process-indicative data. Two types of appropriate data were identified, namely output-electrical current and voltage, plus tri-axial acceleration (vibration). The second objective of this work was data quality analysis to avoid the garbage-in-garbage-out syndrome. Quality analysis identified more than $10 \%$ of the current data as having consecutive values that are constant, or that saturate at an extreme value. Consequently, the electrical data were not analyzed further. The third objective was conditionchange analysis to indicate operational stress under non-ideal operation and machine degradation in proportion to the operational stress. Application of ORNL's novel phase-space dissimilarity measures to the vibration power quantified the rising operational stress in direct proportion to the less-than-full-load power. We conclude that ORNL's technology is an excellent candidate to meet the U.S. Army's need for equipment prognostication.
\end{abstract}




\section{INTRODUCTION}

Real-time prognostication of mission-critical equipment is required to avoid unexpected failures. Typical failures include structural cracking, misalignment, imbalance, short-circuit, broken gears, bearing faults, dust clogging, exhaust deposits on internal parts, and severe wear from wind-blown particulates. Recent information-technology developments (e.g., low-form-factor micro-processors; low-cost, wireless, reducedsize sensors; mesh networking) can now be combined with advanced-prognostics software for longer prediction horizons, while adding minimal weight and bulk.

ORNL staff have developed and patented a novel statistical method that detects condition change from noisy, multi-channel, time-serial data. ORNL has demonstrated the prognostic technology for both biomedical ${ }^{1-15}$ and machine applications ${ }^{15-26}$. Specific machine demonstrations to date include both accelerated failure tests and seeded faults in motors and motor-driven components:

○ Detection of progressively larger drill bit wear from spindle-motor current ${ }^{21}$;

- Distinction between different states for (un)balanced centrifugal pump from motor power ${ }^{21}$;

- Imbalance and misalignment faults in a motor-driven pump from electrical power ${ }^{24}$;

- Forewarning of gear failure from torque and vibration data ${ }^{22}$;

- Forewarning of bearing failure from vibration data ${ }^{22}$;

- Motor faults (air-gap offset, cut rotor, turn-to-turn short, imbalance) from power ${ }^{23}$;

- Detection of progressively larger crack in rotating blade from vibration and electrical power ${ }^{22}$; and

- Forewarning of structural failure from stress and strain data ${ }^{18-20,25}$.

The technology readiness level (TRL) is five, involving integrated, high-fidelity demonstration of the technology components for realistic environments.

The model-independent, data-driven approach quantifies dynamical change in nonlinear systems from timewindowed data sets. The method first rejects inadequate-quality data. Next, a novel filter removes confounding artifacts (e.g., fundamental sinusoid in electrical data). The artifact-filtered data then are converted to a discrete dynamical signature in the form of a statistical distribution function (DF) via timedelay phase-space reconstruction. Dissimilarity measures quantify condition change between the baseline (normal state) DF and subsequent test case DFs. Several sequential occurrences of the dissimilarity measures above a threshold indicate significant change, as a forewarning of failure. This approach also provides an indication of failure onset. This approach has been demonstrated for motors and motor-driven components over more than three orders of magnitude in power (0.25 to 800-HP). PDF copies of our reports ${ }^{1-26}$ and patents $^{27-34}$ are available at the author's publications link, http://computing.ornl.gov/cse_home/staff/hively.shtml.

The objectives of this work are: (1) identification of easily-acquired, process-indicative data for the machine's health status; (2) data quality analysis to avoid the garbage-in-garbage-out syndrome; (3) condition-change analysis to indicate operational stress under non-ideal operation and machine degradation in proportion to the operational stress; and (4) forewarning of failure if it occurs. The long-term goal (not for the present work) is determination of the remaining useful operational life of the TQG (Figure 1), or equivalently an estimate for the time to failure. This report is organized as follows. Section 2 provides background information for the work. Section 3 describes the analysis methodology. Section 4 discusses the results for the TQG application. Section 5 presents the conclusions. 


\section{BACKGROUND}

The need for reliable electrical power in the battlefield environment is a requirement that cuts across all military services and all locations for the foreseeable future. These power systems must be portable, lightweight, quiet, electronically controlled, and continuously operable for long periods on a variety of fuels in extreme environmental conditions. Previous ORNL work ${ }^{35}$ for the U.S. Department of Defense's Mobile Electric Power Program assessed the state of the art in key power technologies, including engines, alternators, power electronics, digital control, and diagnostics and prognostics. The goal was a set of design recommendations for future generators as a TQG replacement to take advantage of advanced technologies under the above usage constraints.

Subsequent ORNL work ${ }^{36}$ developed a proof-of-concept 8-kW unit for the Mobile Electric Power Program on the basis of the earlier recommendations ${ }^{35}$. The requirements for this unit were: 50,60 , and $400 \mathrm{~Hz}$ from one unit; reduction of the generator-set weight by up to $55 \%$; a similar reduction in volume; increase in fuel efficiency; maximal flexibility; low acoustic signature ( $65 \mathrm{dBA}$ at $7 \mathrm{~m})$; low cost; high system reliability; and all on an aggressive proof-of-concept schedule. The digital controls for this unit allowed a digital signal processor (DSP) to monitor, collect, and store system data for analysis in the background. Insufficient time had elapsed during the testing period for failures to be assessed.

Condition-based maintenance enhances reliability and operational readiness by providing indicators about the equipment's present state (diagnostic), as well as an estimate for its future state (prognostic). The advantages of condition-based maintenance include:

- Increase in availability;

- Reduction in downtime;

○ Reduction in mission aborts arising from equipment failure;

- Improvement in management and planning of maintenance;

- Lower maintenance cost;

- Verification of equipment condition prior to deployment;

- Identification of repair/replacement needs before failure;

- Reduction in needs for additional diagnostic equipment; and

- Greater safety.

The bottom line is higher mission success rate at lower cost in terms of lives, equipment, and dollars.

The previous work ${ }^{35}$ noted that reliable prognostics are very difficult for a variety of reasons, including different degradation rates for various machine components, depending on their initial condition, service environment, and maintenance history. Prediction of time-to-failure requires up-to-date trends in key parameters that are related to component condition and life span. Typical indicators include lubrication oil pressure, engine temperature, and fuel level, as indicators of remaining life in the lubrication oil and oil filter, air filter, fuel filter, fan belt, and fuel injector. That work noted that $60-70 \%$ of TQG problems result from buildup of unburned fuel (wet stacking) and carbon residue in the engine and exhaust system. Wet stacking occurs when the TQG runs in an under-loaded condition, which is accompanied by lower operating temperature and increased vibration.

The major roadblocks to prognostication include ${ }^{37}$ : (a) incomplete understanding of fault evolution and failure physics; (b) lack of predictive methodologies for unsteady failure signatures; (c) ignorance about controlling parameters; and (d) emulation of a real operating environment. Our present approach addresses items (a)-(b) by quantifying the (non-stationary) condition change as a sequence of nonlinear statistical signatures; item (c) by associating change in the controlling parameter with the equipment response; and item (d) by designing, running, and analyzing tests that are similar to real-world operations. Previous ORNL work ${ }^{16}$ provided a brief history of dynamical machine analysis over the last 40 years, which will not be repeated here. 


\section{ANALYSIS METHODOLOGY}

For the reader's convenience, we summarize the analysis methodology ${ }^{15-16}$, utilizing three basic approaches, namely conventional statistical measures, traditional nonlinear measures, and ORNL's novel phase-space dissimilarity measures. A process-indicative scalar signal, $e$, is sampled at equal time intervals, $\tau$, starting at an initial time, $t_{0}$, yielding a time-serial sequence of $N$ points, $e_{i}=e\left(t_{0}+i \tau\right)$. Artifacts are removed from this data with a zero-phase quadratic filter ${ }^{34}$ that performs better than conventional filters. This filter uses a moving window, with the same number of data points, $w$, on either side of a central point. A parabola is fitted in the least-squares sense over this window of $2 w+1$ data points. The central point of the fit is an estimate the low-frequency artifact, $f_{i}$. The residual (artifact-filtered) signal, $g_{i}=e_{i}-f_{i}$, has essentially no low-frequency artifact activity. Figures 2-6 illustrate a low-frequency artifact in TQG electrical data, namely the well-known sinusoidal variation, which otherwise obscures the useful dynamical information ("noise" in the view of conventional analysis). All subsequent analysis uses this artifact-filtered data, $g_{i}$.

Conventional statistical measures ${ }^{38}(\mathrm{CSM})$ provide a general characterization of data. Typical CSM are the mean: $\bar{g}=\Sigma_{i} g_{i} / N$ (the sum over $i, \Sigma_{i}$, includes $N$ points in the analysis window); the absolute average deviation, $a=\Sigma_{i}\left|g_{i}-\bar{g}\right| / N$; and the sample standard deviation, $\sigma=\left[\Sigma_{i}\left(g_{i}-\bar{g}\right)^{2} /(N-1)\right]^{1 / 2}$. Higher moments about the mean are skewness (third moment): $S K=\Sigma_{i}\left(g_{i}-\bar{g}\right)^{3} / N \sigma^{3}$, and kurtosis (fourth moment), KT $=\Sigma_{i}$ $\left(g_{i}-\bar{g}\right)^{4} / N \sigma^{4}-3$. Additional measures are the minimum, $g_{n}$, and maximum, $g_{x}$, in the signal. A time-scale measure is the average number of time steps per cycle: $m=N /\left[\left(n_{c}-1\right) / 2\right] \approx 2 N / n_{c}$, for $n_{c} \gg 1\left(n_{c}=\right.$ average number of crossings of the mean). Another time-scale measure is the first zero, $Z$, in autocorrelation function, which is defined as: $A(j)=\Sigma_{i}\left(g_{i}-\bar{g}\right)\left(g_{i+j}-\bar{g}\right) /(N-j) \sigma^{2}$. CSM are useful in the analysis of linear processes, but typically provide inconsistent discrimination of condition change in nonlinear systems. They are included here for completeness and comparison.

Traditional nonlinear measures (TNM) can be useful for characterization of nonlinear data. One is the maximum-likelihood correlation dimension ${ }^{39-40}, D=-M\left\{\Sigma_{i j} \ln \left[\left(\delta_{i j} / \delta_{0}-\delta_{n} / \delta_{0}\right) /\left(1-\delta_{n} / \delta_{0}\right)\right]\right\}^{-1}$, which measures complexity. Here, $M$ is the number of randomly-sampled pairs of phase-space (PS) points. The distance between PS-point pairs, $i$ and $j$, is $\delta_{i j}=\max (0 \leq k \leq m-1)\left|g_{i+k}-g_{j+k}\right|$, where $m$ is the average number of data points per cycle, as defined above. The distance $\delta_{n}$ is the scale length that is associated with noise. Distances are normalized with respect to a nominal scale length, $\delta_{0}$, which is a balance between sensitivity to local dynamics (typically at $\delta_{0} \leq 5 a$ ) and avoidance of excessive noise (typically at $\delta_{0} \geq a$ ). Here, the symbol, $a$, denotes the absolute average deviation (defined in the paragraph on CSM) as a robust indicator of variability $^{41}$. Another typical TNM is Kolmogorov entropy (K-entropy), $K$, which measures the rate of information loss per unit time (e.g., bits per second as a measure of predictability), and is the sum of the positive Lyapunov exponents. Positive, finite $K$ is generally viewed as an indication of chaotic dynamics. Very large entropy indicates a stochastic (totally unpredictable) phenomenon. $K$ is estimated from the average number of time steps, $b_{i}$, for two PS points, initially within $\delta \leq \delta_{0}$, to diverge to $\delta>\delta_{0}$. The maximumlikelihood form of Schouten et $a l^{41}$ is $K=-f_{s} \log (1-1 / \underline{b})$, with $\underline{b}=\Sigma_{i} b_{i} / M$ for $M$ point pairs. The datasampling rate is $f_{s}$. A third TNM is the mutual information function (MIF), which measures average bits of information that can be inferred from one measurement about a second, as a function of the time delay between the two signals. Shannon and Weaver ${ }^{42}$ developed the MIF, which was later applied to time series ${ }^{43}$. The first minimum in the MIF, $M_{1}$, gives the average de-correlation time. The MIF is: $I(q, r)=I(r, q)=H(q)+$ $H(r)-H(r, q)$. Here, $H$ is the entropy: $H(q)=-\Sigma_{i} P\left(q_{i}\right) \log _{2}\left[P\left(q_{i}\right)\right]$ and $H(q, r)=-\Sigma_{i j} P\left(q_{i}, r_{j}\right) \log _{2}\left[P\left(q_{i}, r_{j}\right)\right]$. One set of measurements is $Q=\left\{q_{1}, q_{2}, \ldots, q_{N}\right\}$, with associated occurrence probabilities, $P\left(q_{1}\right), P\left(q_{2}\right), \ldots$, $P\left(q_{N}\right)$. A second measurement set is $R=\left\{r_{1}, r_{2}, \ldots, r_{N}\right\}$, with a time delay relative to $Q$, and with occurrence probabilities $P\left(r_{1}\right), P\left(r_{2}\right), \ldots, P\left(r_{N}\right) . P\left(q_{i}, r_{j}\right)$ is the joint probability that both states occur simultaneously. TNM usually do a poor job of discriminating condition change, but are also included for comparison and completeness. 
The $g_{i}$-data are converted into $S$ discrete (symbolized) values ${ }^{16}, s_{i}$, namely $0 \leq s_{i} \leq S-1$. Equiprobable symbols are formed by ordering all $N$ of the base case artifact-filtered, time-serial data points from the smallest to largest value. The first $N / S$ of these ordered values correspond to the first symbol, 0 . Ordered data values $(N / S)+1$ through $2 N / S$ correspond to the second symbol, 1, and so on. Equiprobable symbols have non-uniform partitions in the signal amplitude with the same occurrence frequency of $g_{i}$ values by construction, and thus have no information about the dynamical structure. In contrast, symbols with uniform partitions (uniform symbols), $s_{i}=S\left(g_{i}-g_{n}\right) /\left(g_{x}-g_{n}\right)$, have inherent dynamical structure before beginning the PS reconstruction, where $g_{x}$ and $g_{n}$ are the maximum and minimum values of the $g_{i}$-data, respectively. Thus, one advantage of equiprobable symbols is that dynamical structure arises only from the PS reconstruction, as described below. Moreover, large negative and large positive values of $g_{i}$ have little effect on equiprobable symbolization, but dramatically change the partitions for uniform symbols. The variable, $U E$, is used to designate uniform, $U E=0$, or equiprobable, $U E=1$, symbols.

The time-serial $s_{i}$-data are next converted into a geometric object via phase-space (PS) reconstruction via time-delay vectors, $y(i)=\left[s_{i}, s_{i+\mu}, \ldots, s_{i+(d-1) \mu}\right]$, partitioning the PS into $S^{d}$ hypercubes or bins ${ }^{16}$. Each bin can be identified by a unique integer, $J$, via base- $S$ arithmetic, $J=\Sigma_{m} s_{i+m \mu} S^{m}$, where the summation, $\Sigma_{m}$, is over the range $0 \leq m \leq d-1$. Additional data channels may add more information about the inter-connected dynamics, implying that a multi-channel PS-vector could contain more information than a single channel. The multi-channel PS vector is: $y(i)=\left[s_{i}(1), s_{i+\mu}(1), \ldots, s_{i+(d-1) \mu}(1), \ldots, s_{i}(\mathrm{C}), s_{i+\mu}(\mathrm{C}), \ldots, s_{i+(d-1) \mu}(\mathrm{C})\right]$. Here, the symbol, $s(k)$ denotes values from the $k$-th channel, $1 \leq k \leq C$, for up to $C$ channels. Now, the symbolization divides the multi-channel PS in $S^{C d}$ bins, where the bin identifier is $J=\Sigma_{k} \Sigma_{m} \mathrm{~s}(k)_{\mathrm{i}+m \mu} S^{m+d(k-1)}$. The choice of lag, $\mu$, and embedding dimension, $d$, determines how well the PS reconstruction unfolds the dynamics. An excessively large embedding dimension could result in over-fitting of real data with finite length and noise. Moreover, different observables of a system contain unequal amounts of dynamical information,implying that PS reconstruction could be easier from one choice of variable(s), but more difficult or impossible from another choice. This analysis seeks to balance these caveats for finite-length noisy data.

Conversion of the time-serial data into discrete PS states allows the construction of a statistical distribution function (DF) by counting the number of PS points that occur in each bin ${ }^{16}$. This DF is the discretized density of PS states. $Q_{J}$ and $R_{J}$ denote the population of the $J$-th DF bin for the base case (nominal state), and for a test case (off-normal state), respectively. The test case is compared to the base case by dissimilarity measures, namely the $\chi^{2}$ statistic and $L_{1}$ distance:

$$
\begin{aligned}
& \chi_{n}{ }^{2}=\sum\left(Q_{J}-R_{J}\right)^{2} /\left(Q_{J}+R_{J}\right), \\
& L_{n}=\sum\left|Q_{J}-R_{J}\right| .
\end{aligned}
$$

The sum in Eqs. (1) - (2) is over all of the populated PS bins. In this work, $\chi^{2}$ is not an unbiased statistic for testing a null statistical hypothesis but rather is a relative measure ${ }^{7}$ of dissimilarity between the two DFs. The $L_{1}$ distance is the natural metric for DFs by its direct relation to the total invariant measure on the attractor. These measures account for changes in the geometry and visitation frequency of the attractor. Consistent calculation requires the same number of points in both the base and test case DFs, identically sampled; otherwise the distribution functions must be rescaled.

The accuracy and sensitivity of the PS reconstruction can be enhanced by connecting successive PS points as prescribed by the underlying dynamics, $y(i) \rightarrow y(i+1)$. A discrete representation of the process flow, $Y(i)=$ $[y(i), y(i+1)]$, is formed by adjoining two successive vectors from the $d$-dimensional reconstructed PS. $Y(i)$ is a $2 d$-dimensional, connected-phase-space (CPS) vector. As before, $Q$ and $R$ denote the CPS DFs for the base case and test case, respectively. The measures of dissimilarity between these two CPS DFs are defined via the $L_{1}$-distance and $\chi^{2}$ statistic, as before: 


$$
\begin{aligned}
& \chi_{c}{ }^{2}=\sum_{J K}\left(Q_{J K}-R_{J K}\right)^{2} /\left(Q_{J K}+R_{J K}\right), \\
& L_{c}=\sum_{J K}\left|Q_{J K}-R_{J K}\right| .
\end{aligned}
$$

The subscript $c$ denotes CPS measures in Eqs. (3)-(4), while the subscript, $n$, in Eqs. (1) - (2) denotes nonconnected PS states. The subscripts, $J$ and $K$, are identifiers for the initial, $y(i)$, and final, $y(i+1)$, PS states, respectively. The value $\mu=1$ results in $d-1$ components of $y(i+1)$ being redundant with those of $y(i)$; this redundancy is allowed to accommodate other data such as discrete points from two-dimensional maps. CPS measures have higher discriminating power than their non-connected counterparts. Indeed, these measures rigorously satisfy the inequalities ${ }^{6}: \chi_{n}^{2} \leq L_{n}, \chi_{c}^{2} \leq L_{c}, L_{n} \leq L_{c}$, and $\chi_{n}^{2} \leq \chi_{c}^{2}$.

The quantities in Eqs. (1)-(4) are called phase space dissimilarity measures (PSDM). These measures discriminate between different chaotic regimes, and transitions between regular and chaotic regimes. Such discrimination is impossible with traditional nonlinear measures (e.g., Lyapunov exponents, Kolmogorov entropy, correlation dimension ${ }^{44}$ ). Straightforward methods exist ${ }^{45-47}$ for discriminating between regular and chaotic dynamics, or for detecting the transition between these regimes. The reason for this improvement is rather simple: discrimination by TNM is based on a difference of averages, while discrimination via PSDM is based on summing the absolute value of differences.

The disparate range and variability of these measures are difficult to interpret, especially for noisy data. A consistent means of comparison is via renormalized dissimilarity measures (RDM) ${ }^{5-6}$, which are defined by the following form: $U(V)=\left|V_{i}-\bar{V}\right| / \sigma_{1}$, as the number of standard deviations, $\sigma_{1}$, that the test case deviates from the base case mean. The base case corresponds to the nominal-state dynamics of the TQG. $V$ denotes a phase-space dissimilarity measure from the set, $V=\left\{L_{n}, L_{c}, \chi_{n}{ }^{2}\right.$, and $\left.\chi_{c}{ }^{2}\right\}$. We obtain the mean value, $\bar{V}$, of the dissimilarity measure by comparison among the $B(B-1) / 2$ unique combinations of the $B$ base case cutsets, with a corresponding sample standard deviation, $\sigma_{1}$. We subsequently compare each contiguous, nonoverlapping test case cutset to each of the $B$ base case cutsets, and obtain the corresponding average dissimilarity value, $V_{i}$, of the $i$-th analysis window for each dissimilarity measure. A statistically significant trend in the RDM indicates equipment degradation for failure forewarning.

The best analysis parameters, $\{N, w, B, S, d, \mu, U E\}$, depend not only on the system, but also on the specific data under consideration. From experience, the longest analysis window of $N$ points is best, limited by the total length of the data, $N=95,550$, as explained below. The choice of the artifact-filter half-width is $w=250$ to remove the secular term in the time-integration of acceleration, also from experience. The value for the number of base case cutsets is $B=10$, as a balance between a reasonably short quasi-stationary period of "normal" dynamics and a sufficiently long period for statistical significance. Our analysis over the remaining parameters, $\{S, d, \mu, U E\}$, proceeds as follows: (a) choose the parameter set; (b) compute the renormalized PS dissimilarity measures for the specific machine data; and (c) exhaustively search over the parameters for the best indication of condition change. 


\section{RESULTS}

The specific machine application is the Army's 10-kW Tactical Quiet Generator (TQG), which is a constantspeed (and constant voltage) diesel motor-generator (Figure 1). Operation under less-than-full-load conditions allows unburned fuel to escape along with exhaust gases. This unburned fuel is deposited continuously on internal components (wet stacking), resulting in degraded operation, and eventually failure. Thus, nominal operation is at full load, while less-than-full load corresponds to an increasing-severity operational stress.

Discussions with the sponsor identified two kinds of easily acquired, process-indicative data. One is electrical data from the generator-output: (single phase) current, $I_{i}$, and voltage, $V_{i}$, versus time, $t_{i}$. Another is tri-axial vibration data, $\boldsymbol{a}_{i}$, versus time, $t_{i}$, from a hard-mounted accelerometer on the diesel motor. The data are sampled at $100 \mathrm{kHz}$ for 10 seconds, or $10^{6}$ samples. The sponsor supplied both kinds of data for various generator-load conditions $(10,7.5,5,2.5,0.5$, and $0 \mathrm{~kW})$. These data satisfy the first objective for this work, namely identification (and acquisition) of process-indicative TQG data.

Data quality analysis verifies important features in the data: proper number of data points; any intervals with unchanged amplitude; saturation at high or low limits as an indicator of improper data scaling; consistent amplitude across datasets in the test sequence; adequate sampling rate; excessive periodic content; and excessive noise. An adequate sampling rate should span the de-correlation time with a sufficient number of time samples. The specific de-correlation-time measures are the first minimum in the mutual information function ( $\geq 4$ time steps) and the first zero in the auto-correlation function ( $\geq 4$ time steps). Excessive periodicity obscures the under-lying nonlinear dynamics and has more than $50 \%$ of the total area under the two largest peaks in the Fourier spectrum versus frequency. Excessive noise obliterates the useful information with disorderly signal values. Consequently, a measure of order in the signal (Shannon entropy, $E$ ) versus the number of uniform data symbols $(S)$ allows determination of the average number of bits of information $(b)$ in the data as the maximum in $E$ versus $S=2^{b}$; less than five bits of information corresponds to excessive noise. The garbage-in-garbage-out syndrome is avoided by rejection of data that fails one or more of these tests.

Figures 2-6 illustrate the electrical data with a classic sinusoidal variation in output voltage, $V_{i}$, current, $I_{i}$, and single-phase electrical power, $I_{i} V_{i}$. The electrical current and power display "noise," which is a qualitative indicator of the machine stress. As the stress on the TQG increases (i.e., as the output load decreases), this noise increases in amplitude and becomes more complex. No-load electrical data were unavailable, because the resultant current is zero. The quality analysis rejected all of the electrical data, which have a significant fraction $(\geq 10 \%)$ of consecutive values that are constant, or that saturate at the maximum or minimum value.

The acceleration data are of high quality, except for the $10 \mathrm{~kW}$-load data, which were corrupted and unusable. This finding satisfies the second objective, namely rejection of inadequate quality data. Subsequent analysis focuses on the vibration data at TQG-power levels from 0 to $7.5 \mathrm{~kW}$ without the corrupted 10-kW case.

Previous work ${ }^{16}$ determined that power is an excellent indicator of machine condition. Consequently, this work focuses on instantaneous vibration power, which is $p \propto \boldsymbol{a} \bullet \boldsymbol{a} d t$. This choice is certainly not unique. For example, one component of acceleration might be adequate. The advantage of vibration power is a single channel of data (rather than several channels) with all of the three-dimensional dynamics and with a proportionate reduction in computational effort to quantify the condition change. Conversion of the tri-axial acceleration data to vibration power uses an artifact-filter half-width of $w=250$ to eliminate the secular term, yielding 955,500 data samples at each of the five power levels. The five resultant datasets of vibration power were concatenated into a single file for ease of analysis, beginning with the lowest stress case $(7.5 \mathrm{~kW})$ as the baseline, and decreasing in power to the highest stress case $(0 \mathrm{~kW})$. Figure 7 illustrates the tri-axial acceleration data, which are very nonlinear and complex. This data structure is very similar across all of the other load conditions, which are not shown here.

Figure 8 shows the various conventional statistical measures versus TQG load. The top plot shows a 
monotonic rise with increasing TQG load in the minimum, maximum, absolute average deviation, and standard deviation. However, this monotonic rise does not show the desired linear change. The middle plot shows no consistent change in the skewness $(S K)$, kurtosis $(K T)$, or mean with increasing load on the TQG. The bottom plot shows no consistent change in $m$ (time-steps per cycle or TSPC), while $Z$ decreases monotonically (but somewhat erratically) with increasing load on the TQG. A summary of these trends in Table 1 shows that no CSM provides change in proportion to decreasing load.

Figure 9 illustrates the variation of TNM with TQG load. These plots are shown with error bars of one standard deviation, corresponding to ten contiguous, non-overlapping analysis windows $(N=95,550)$ for each TQG load. The top plot shows that correlation dimension varies erratically with TQG load, as does the Kolmogorov entropy (middle plot). The first minimum in the mutual information function (bottom plot) rises from 0 to $500 \mathrm{~W}$, is flat between 500 and $5000 \mathrm{~kW}$, and rises again from 5 to $7.5 \mathrm{~kW}$. Consequently, the TNM do not show a consistent change in TQG stress with decreasing load.

As discussed in Sect. 2, phase-space dissimilarity measures are determined via Eqs. 1- 4 over a broad range of parameters, namely: $1 \leq \lambda \leq 100$, for both uniform and equiprobable symbols. Double-precision arithmetic on our 32-bit personal computers limits the combination of PS dimension, $d$, and the number of symbols, $S$, according to the expression, $S^{2 d} \leq 2^{52}$, or $S \leq S_{X}=\operatorname{INT}\left(2^{26 / d}\right)$, where the function, INT, converts a decimal number to the next lowest integer. Table 2 shows the resultant upper range (center column), $S_{X}$, which is further restricted in these analyses to $2 \leq d \leq 10$ and $2 \leq S \leq 300$ (right column) on the basis of previous experience ${ }^{15-16}$. This analysis also uses ten contiguous, non-overlapping analysis windows $(N=95,550)$ for each TQG load, from which the average and sample standard deviation of each PSDM is determined.

A least-squares linear fit is used to determine the sensitivity (slope of the fit) of each dissimilarity measure to the change in TQG power. A second measure of the fit is the sum of squares (SSQ) of the differences between the fit and the dissimilarity measures. Figure 10 shows a plot of the sum of the slopes from this fit versus the corresponding SSQ value. The points along the upper left boundary of this plot are the best fits, namely the largest sum-of-slopes for a given SSQ-value. Figure 11 shows the best set of renormalized dissimilarity measures for the set of analysis parameters $(d=3, S=240, \lambda=48$, and equiprobable symbols). All of the dissimilarity values are within one standard deviation of the straight-line fit. This parameter set also provides a monotonic change in the dissimilarity measures with TQG power; the sole exception to this constraint is a non-monotonic change in $\chi_{n}^{2}$ from 0 to $500 \mathrm{~W}$ (upper left portion of the top plot). This more consistent change in phase-space dissimilarity measures is in contrast to the inconsistent changes in the conventional statistical measures and in the traditional nonlinear measures, as discussed in the preceding paragraphs. These results satisfy the third objective of this work. Namely, the consistent change in phase-space dissimilarity measures is proportional to the operational stress under non-ideal operation, indicating degradation in machine performance that is proportional to the operational stress. No failure occurred in the present TQG data, so the fourth objective (forewarning of failure) could not be tested by the present analysis.

The sponsor performed a second set of TQG experiments in September of 2007 to acquire data for nine generator-load levels $(10,7.5,5.0,2.5,2.0,1.5,1.0,0.5$, and $0 \mathrm{~kW})$. Each dataset was sampled at $50 \mathrm{kHz}$ for 10 seconds, or 500,000 samples. The objective of this second experiment was to improve the demonstration of PSDM usefulness over the previous experiment. The electrical and accelerometer data exhibited the same structure as in Figs. 2-7 (not shown here). The data quality analysis showed that all of the electrical data have a significant fraction ( $10 \%$ or more) of consecutive values that are constant, or that saturate at the maximum or minimum value. Consequently, the electrical data are not analyzed further. No quality failures occurred in the accelerometer data, which is the focus of the second round of analysis. Accelerometer data were acquired from two locations, namely from the generator enclosure (as shown in Fig. 1), and from the engine block (as shown in Fig. 12). Both sets of accelerometer data were analyzed, as discussed next.

As before, this work uses instantaneous vibration power ${ }^{16}$, which is $p \propto \boldsymbol{a} \bullet \int \boldsymbol{a} d t$. Also as before, conversion of the tri-axial acceleration data to vibration power uses an artifact-filter half-width of $w=250$ to eliminate the 
secular term. The nine resultant datasets were concatenated into a single file for ease of analysis, beginning with the lowest stress case $(10 \mathrm{~kW})$ as the baseline, and decreasing in power to the highest stress case $(0 \mathrm{~kW})$. These acceleration data are very nonlinear and complex (not unlike Fig. 7), and are not shown here.

Analysis of this second set of data concentrated on the phase-space dissimilarity measures, because the previous analysis showed inconsistent discrimination via conventional statistical measures and traditional nonlinear measures. As before, the best parameters were found by an exhaustive search over a broad range of potential values, namely: $1 \leq \lambda \leq 100$, for both uniform and equiprobable symbols, $2 \leq d \leq 10$ and $2 \leq S \leq 300$ (with the joint restrictions on possible values of $d$ and $S$, as discussed above, and summarized in Table 2). Further analysis verified that higher dimensions ( $11 \leq d \leq 26$ for $1 \leq \lambda \leq 100$ and $0 \leq U E \leq 1)$ yield inferior results. This analysis also uses ten contiguous, non-overlapping analysis windows $(N=50,000)$ for each TQG load. Figure 13 shows the generator-casing-accelerometer PSDM results, which increase monotonically and linearly with decreasing load on the generator. Twenty-five (25) of the 36 PSDM values (69\%) are within one sample standard deviation of the linear fit, which is not inconsistent with a normal statistical distribution. Figure 14 shows the engine-block-accelerometer PSDM results, which also increase monotonically and linearly with decreasing load on the generator. Twenty-four (24) of the 36 PSDM values (67\%) are within one standard deviation of the linear fit, which again is not inconsistent with a normal distribution. These results show that PSDM provide consistent indication of the stress on the TQG as the load power changes.

These results (as summarized in the below in-text table) merit further discussion. The phase-space dimension is low for accelerometer data from the generator enclosure $(2 \leq d \leq 3)$, but is larger for the engine block $(9 \leq d$ $\leq 10)$ data. The reason for this disparity is that the engine block is heavy and structurally stiff with more complex and higher-frequency dynamics than the light and structurally compliant generator enclosure. The disparity between the two generator-enclosure results is also worthy of comment and some further analysis. The original baseline (June-2007) was for a load of 7.5-kW, which imposes some stress on the TQG. The more recent analysis used a full-power $(10-\mathrm{kW})$, low-stress baseline with lower complexity dynamics $(d=2)$ and only a few symbols $(S=4)$ to capture that variability over lower frequencies (corresponding to a larger time lag, $\mu=81$ ). By contrast, the somewhat-stressed, $7.5-\mathrm{kW}$ baseline from June-2007 has more complex dynamics $(d=3)$ that require more symbols to capture the variability $(S=240)$ at higher frequencies (corresponding to a shorter time lag, $\mu=48$ ).

\begin{tabular}{|c|c|c|c|c|c|c|c|}
\hline Date & Baseline & Accelerometer location & $\underline{d}$ & $\underline{S}$ & $\underline{\mu}$ & Symbol type & Figure \\
\hline June-2007 & $7.5 \mathrm{~kW}$ & generator enclosure & 3 & 240 & 48 & equiprobable & 11 \\
\hline Sept.-2007 & $10 \mathrm{~kW}$ & generator enclosure & 2 & 4 & 81 & uniform & 13 \\
\hline Sept.-2007 & $10 \mathrm{~kW}$ & engine block & $9-10$ & 5 & 50 & uniform & 14 \\
\hline
\end{tabular}

Figure 15 shows the Fourier spectra for the two generator-enclosure baselines to confirm this discussion. The top plot (10-kW baseline from the Sept-2007 experiment) shows a broad, flat tail with a Fourier amplitude of $\sim 3 \times 10^{4}$ for frequencies above $8 \mathrm{kHz}$. The bottom plot (7.5-kW baseline from the June-2007 experiment) shows higher amplitudes $\left(\sim 10^{5}\right)$ in the flat portion of the tail $(5-13 \mathrm{kHz})$, corresponding to more energy in the higher-frequency dynamics of the higher-stress TQG state. The very broad tails in these Fourier spectra are indicative of the nonlinear dynamics, for which the PSDM provide consistent condition change. 


\section{CONCLUSIONS}

This work analyzes vibration power for comparison of conventional statistical measures (CSM), traditional nonlinear measures (TNM), and phase-space dissimilarity measures (PSDM) as indicators of condition change in the Army's Tactical Quiet Generator. Recent work by our team showed very similar results for other machines and types of data ${ }^{16}$. Namely, the PSDM provide a more consistent correlation with fault progression, than the CSM and $\mathrm{TNM}^{22}$. Table 3 summarizes recent results for forewarning of seeded (S) faults and accelerated (A) failures in various machines and equipment; starred $\left(^{*}\right)$ entries had multiple repetitions of the same experiment to demonstrate reproducibility. CSM include minimum, maximum, average, sample standard deviation, skewness, kurtosis, average time steps per cycle, and first zero in the auto-correlation function. The TNM include first minimum in the mutual information function as a measure of decorrelation time, correlation dimension as a measure of complexity, and Kolmogorov entropy as a measure of information loss rate. PSDM are the $\chi^{2}$ statistic and $L_{1}$ distance between the time-delayed reconstructions of the PS-distribution functions.

PSDM consistently show better discrimination power for machine prognostication, than either CSM or TNM. The reason for the improved performance of PSDM is rather simple. CSM and TNM compare averages, while PSDM are the sum over the absolute difference between the two phase-space states. In addition, the enhanced discrimination power facilitates use of PSDM on noisier data. The sensitivity and robustness of PSDM depend both on the data quality and on the phase-space reconstruction parameters. Indeed, (i) data quality can be improved by removal of (known) confounding artifacts from the signal, and (ii) reconstruction parameters can be chosen much closer to their optimal values. Without this information, one must resort to a trial and error procedure, which requires a search over a large subset of the parameter space to obtain the best indication of condition change.

Finally, we mention that this same approach provides forewarning and detection of biomedical events ${ }^{1-15}$. One implementation of this ORNL technology is a hand-held, wireless device ${ }^{10}$ (personal digital assistant, PDA) that acquires and analyzes the data for event forewarning. Since the same approach quantifies condition change for both the biomedical and the machine applications, this hand-held platform can be readily adapted for TQG prognostics. 


\section{REFERENCES}

${ }^{1}$ L. M. Hively, V. A. Protopopescu, N. B. Munro, "Enhancements in Epileptic Forewarning via Phase Space Dissimilarity," J. Clin. Neurophysiol. 22 (December 2005) 402-409.

${ }^{2}$ L. M. Hively and V. A. Protopopescu, "Advanced Physiological Monitoring of FCS Soldiers," Proc. 24th Army Sci. Conf. (Orlando, FL) 29 Nov. - 2 Dec 2004.

${ }^{3}$ L. M. Hively and V. A. Protopopescu, "Channel-Consistent Forewarning of Epileptic Events from Scalp EEG,” IEEE Trans. Biomed. Engr. 50 (May 2003) 584-593.

${ }^{4}$ L. M. Hively and V.A. Protopopescu, "Detection of Changing Dynamics in Physiological Time Series," Proc. ANS Conf. on Nucl. Math. Computational Sci. (Gatlinburg, Tn) 6-11 April 2003.

${ }^{5}$ V. A. Protopopescu, L. M. Hively, P. C. Gailey "Epileptic Event Forewarning from Scalp EEG," invited review paper in J. Clin. Neurophysiol. 18 (May 2001) 223-245.

${ }^{6}$ L.M. Hively, V.A. Protopopescu, P.C. Gailey, “Timely Detection of Dynamical Change in Scalp EEG Signals," Chaos 10 (2000) 864-875.

${ }^{7}$ L.M. Hively, P.C. Gailey, and V.A. Protopopescu, "Detecting Dynamical Change in Nonlinear Time Series," Physics Lett. A 258 (1999) 103-114.

${ }^{8}$ P.C. Gailey, L.M. Hively, V.A. Protopopescu, "Robust Detection of Dynamical Change in EEG," in Proceedings of $5^{\text {th }}$ Experimental Chaos Conference, Orlando, Florida (6/28-7/1/99).

${ }^{9}$ L.M. Hively, P.C. Gailey, V.A. Protopopescu, "Sensitive Measures of Condition Change in EEG Data," Proc. of Int'l workshop Chaos in Brain (Bonn, March 1999) World Scientific Publ.

${ }^{10}$ L.M. Hively, K.L. Kruse, N.B. Munro, and V.A. Protopopescu, "Epilepsy Forewarning Using a HandHeld Device," ORNL/TM-2005/40 (February 2005) Oak Ridge National Laboratory, Oak Ridge, TN.

${ }^{11}$ L. M. Hively, V. A. Protopopescu, J. Joseph, "CRADA Final Report for CRADA Number ORNL990559 - Epileptic Seizure Forewarning by Nonlinear Techniques,” C/ORNL99-0559 (January 2002) Oak Ridge National Laboratory.

${ }^{12}$ L.M. Hively, N.E. Clapp, V.A. Protopopescu, J. Joseph, C. E. Merican, T. Lucht, "Epileptic Seizure Forewarning by Nonlinear Techniques," ORNL/TM-2000/333 (November 2000) Oak Ridge National Laboratory.

${ }^{13}$ L.M. Hively, N.E. Clapp Nonlinear Analysis of Polygraph Data, K/NSP-351 (March 1996) Oak Ridge National Laboratory, Oak Ridge, Tn.

${ }^{14}$ L.M. Hively, N.E. Clapp, C.S. Daw, W.F. Lawkins, Nonlinear Analysis of EEG For Epileptic Seizures, ORNL/TM-12961 (April 1995) Oak Ridge National Laboratory.

${ }^{15}$ V. Protopopescu and L.M. Hively, "Phase-space Dissimilarity Measures of Nonlinear Dynamics: Industrial and Biomedical Applications," Recent Res. Devel. Physics 6 (2005) 649-688.

${ }^{16}$ L.M. Hively and V.A. Protopopescu, "Machine Failure Forewarning via Phase-Space Dissimilarity 
Measures," Chaos 14 (June 2004) 408-419.

${ }^{17}$ V. A. Protopopescu, L. M. Hively, "Forewarning of Machine Failure via Nonlinear Analysis," Proc. Amer. Nucl. Soc., June 2003.

${ }^{18}$ D.E. Welch, L.M. Hively, R.F. Holdaway, "Nonlinear Crack Growth Monitoring", abstract for 33rd National Symp. On Fatigue and Fracture (June 2001) Moran, Wyoming.

${ }^{19}$ D.E. Welch, L.M. Hively, R.F. Holdaway, "Nonlinear Crack Growth Monitoring", Proc. Int'l Mech. Engr. Congress and Exposition (5-10 November 2000) Orlando, Florida.

${ }^{20}$ D.E. Welch, L.M. Hively, R.F. Holdaway, "Nonlinear Crack Growth Monitoring", abstract accepted for 2000 ASM Materials Solutions Conference and Exposition (11 October 2000) St. Louis, Missouri.

${ }^{21}$ L.M. Hively, "Data-Driven Nonlinear Technique for Condition Monitoring," Proc. Maintenance and Reliability Conf., Vol. 1, pp 16.01-16.10 (1997) Knoxville, Tn.

${ }^{22}$ L. M. Hively, V. A. Protopopescu, K. M. Reichard, K. P. Maynard, "Nuclear Energy Research Initiative (NERI), Forewarning of Failure in Critical Equipment at Next-Generation Nuclear Power Plants," ORNL/TM-2003/222, October 23, 2003.

${ }^{23}$ L. M. Hively and V. A. Protopopescu, "Forewarning of Failure in Critical Equipment at Next Generation NPP," Annual Report for NERI2000-109 project (Dec. 2002) ORNL/TM-2002/183.

${ }^{24}$ L. M. Hively, V. A. Protopopescu, M. Maghraloui, and J. W. Spencer, "Annual Report for NERI Proposal \#2000-0109 on Forewarning of Failure in Critical Equipment at Next-Generation Nuclear Power Plants," ORNL/TM-2001/195 (November 2001).

${ }^{25}$ D. E. Welch, L. M. Hively, R. F. Holdaway, "Nonlinear Crack Growth Monitoring,” ORNL-TM-1999/117, October 1999.

${ }^{26}$ L.M. Hively, V.A. Protopopescu, N.E. Clapp, C.S. Daw, Prospects of Chaos Control of Machine Tool Chatter, ORNL/TM-13283 (June 1998).

${ }^{27}$ L.M. Hively, "Methods for improved forewarning of critical events across multiple data channels," U.S. Patent \#7,209,861 (24 April 2007).

${ }^{28}$ L.M. Hively, "Methods for consistent forewarning of critical events across multiple data channels," U.S. Patent \#7,139,677 (21 November 2006).

${ }^{29}$ L.M. Hively, P.C. Gailey, V.A. Protopopescu, "Condition Assessment of Nonlinear Processes," U.S. Patent \#6,484,132 (19 November 2002).

${ }^{30}$ D.E. Welch, L.M. Hively, and R.F. Holdaway, "Nonlinear Structural Crack Growth Monitoring," U.S. Patent \#6,460,012 (01 October 2002).

${ }^{31}$ L.M. Hively, N.E. Clapp, C.S. Daw, W.F. Lawkins, "Epileptic Seizure Prediction By Non-linear Methods," U.S. Patent \#5,857,978 (12 January 1999).

${ }^{32}$ L.M. Hively and E.G. Ng, "Integrated Method for Chaotic Time Series Analysis," U.S. Patent \#5,815,413 (29 September 1998). 
${ }^{33}$ L.M. Hively, N.E. Clapp, C.S. Daw, W.F. Lawkins, "Apparatus and Method for Epileptic Seizure Detection using Nonlinear Techniques,” U.S. Patent \#5,743,860 (28 April 1998).

${ }^{34}$ N.E. Clapp and L.M. Hively, "Method and Apparatus for Extraction of Low-Frequency Artifacts from Brain Waves for Alertness Detection,” U.S. Patent \#5,626,145 (6 May 1997).

${ }^{35}$ J.B. Andriulli, A.E. Gates, H.D. Haynes, L.B. Klett, S.N. Matthews, E.A. Nawrocki, P.J. Otaduy, M.B. Scudiere, T.J. Theiss, J.F. Thomas, L.M. Tolbert, M.L. Yauss, and C.A. Voltz, “Advanced Power Generation Systems for the $21^{\text {st }}$ Century: Market Survey and Recommendations for A Design Philosophy," ORNL/TM-1999/213 (Oak Ridge National Laboratory, Oak Ridge, TN) 1999.

${ }^{36}$ J.B. Andriulli, M.B. Scudiere, C.P. White, G. Farquaharson, T.J. Theiss, C.W. Ayres, C.L. Coomer, D. Eddy, H.D. Ferguson, E.J. Hardin, H.D. Haynes, M.S. Hileman, D.K. Irick, L.B. Klett, P.J. Otaduy, G.W. Ott, W. Peterson, L.E. Sieber, J.F. Thomas, and L.M. Tolbert, "Development of Proof-of-Concept Units for the Advanced Medium-Sized Mobile Power Sources (AMMPS) Program," ORNL/TM-2001/222 (Oak Ridge National Laboratory, Oak Ridge, TN) 2002.

${ }^{37}$ NIST Workshop on Condition-Based Maintenance, http://www.nist.gov/www/cbm/cbm_wp1.htm.

${ }^{38}$ M. Abramowitz and I.A. Stegun (ed.), Handbook of Mathematical Functions, U.S. Government Printing Office, Washington, D.C. (1964).

${ }^{39}$ F. Takens, Lecture Notes in Mathematics 1125 (1984) 99-106.

${ }^{40}$ J. C. Schouten, F. Takens, and C. M. van den Bleek, Phys. Rev. E 50 (1994) 1851-1861.

${ }^{41}$ J. C. Schouten, F. Takens, and C. M. van den Bleek, Phys. Rev. E 49 (1994) 126-129.

${ }^{42}$ C. E. Shannon and W. Weaver, The Mathematical Theory of Communication (Univ. of Illinois Press, Urbana, 1949).

${ }^{43}$ A. M. Fraser and H. L. Swinney, Phys. Rev. A $\underline{33}$ (1986) 1134-40.

${ }^{44}$ L. Qu, A. Xie and X. Li, "Study and performance evaluation of some nonlinear diagnostic methods for large rotating machines," Mech. Mach. Theory 28 (1993) 699-713.

${ }^{45}$ J. P. Eckmann and D. Ruelle, Rev. Mod. Phys. 57 (1985) 617-655.

${ }^{46}$ H. D. I. Abarbanel, Analysis of Observed Chaotic Data (Springer, New York) 1996.

${ }^{47}$ A. Cover, J. Reneke, S. Lenhart, and V. Protopopescu, Math. Models and Meth. in Appl. Sci. 7 (1997) 823-845. 
Table 1: Summary of trends in CSM from figure 8

\begin{tabular}{|l|l|}
\hline \multicolumn{1}{|c|}{ Conventional statistical measure } & Trend \\
\hline Minimum, $a_{n}$ & Monotonic, but not linear \\
\hline Maximum, $a_{x}$ & Monotonic, but not linear \\
\hline Standard deviation, $\sigma$ & Monotonic, but not linear \\
\hline Absolute average deviation, AAD & Monotonic, but not linear \\
\hline Skewness, SK & None \\
\hline Kurtosis, KT & None \\
\hline Mean & None \\
\hline First zero in auto-correlation function, & Monotonically \\
$Z$ & decreasing \\
\hline Time steps per cycle, TSPC & None \\
\hline
\end{tabular}

Table 2: Range of phase-space symbols, $S$, versus phase-space dimension, $d$

\begin{tabular}{|c|c|c|}
\hline$d$ & $2 \leq S \leq S_{X}$ & $2 \leq S \leq S_{X}^{\prime}$ \\
\hline 2 & 8192 & 300 \\
3 & 406 & 300 \\
4 & 90 & 90 \\
5 & 36 & 36 \\
6 & 20 & 20 \\
7 & 13 & 13 \\
8 & 9 & 9 \\
9 & 7 & 7 \\
10 & 6 & 6 \\
\hline 11 & 5 & not used \\
$12-13$ & 4 & not used \\
$14-16$ & 3 & not used \\
$17-26$ & 2 & not used \\
\hline
\end{tabular}




\section{Table 3: Summary of recent machine failure forewarning results}

$\underline{\text { Data Provider }}$

1) EPRI (S)

2) $\operatorname{EPRI}(\mathrm{S})$

3) $\operatorname{EPRI}(\mathrm{S})$

4) Otero (S)

5) PSU/ARL (A)*

6) PSU/ARL (S)

7) PSU/ARL (A)

8) $\mathrm{ORNL}^{*}$

9) ORNL
Equipment and Type of Failure 800-HP electric motor: air-gap offset

800-HP electric motor: broken rotor

500-HP electric motor: turn-to-turn short

1/4-HP electric motor: imbalance ${ }^{23}$

30-HP motor: overloaded gearbox ${ }^{23}$

crack in rotating blade ${ }^{16}$

motor-driven bearing ${ }^{16}$

failure of laboratory structural samples ${ }^{18-20,25}$

machine tool chatter ${ }^{26}$
Diagnostic Data

electrical power ${ }^{23}$

vibration power ${ }^{16}$

electrical power ${ }^{23}$

vibration power ${ }^{16}$

electrical power ${ }^{23}$

vibration power ${ }^{16}$

acceleration

load torque ${ }^{23}$

electrical power ${ }^{23}$

vibration power ${ }^{16}$

motor power

vibration power

vibration power

stress and strain

acceleration

Starred (*) entries had multiple repetitions of the same experiment to demonstrate reproducibility. 

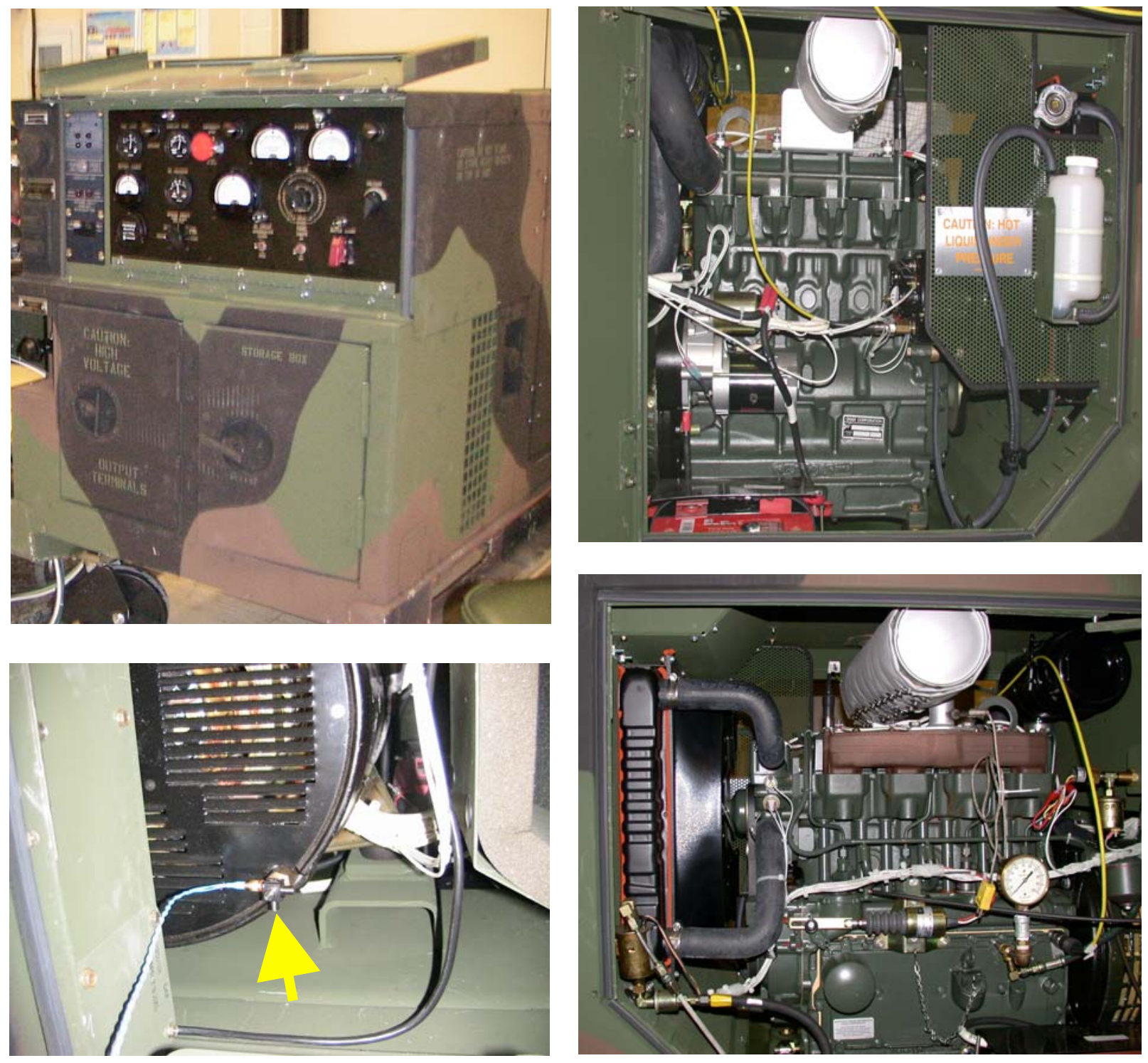

Figure 1: Pictures of the U.S. Army's Tactical Quiet Generator (TQG), showing an external view (top left); an interior view (top right); another interior view (bottom right), including a portion of the generator enclosure in the lower right corner of the picture; and the accelerometer location on the generator enclosure (bottom left) with the yellow arrow pointing to the accelerometer. Pictures are courtesy of the U.S. Army Research Laboratory. 

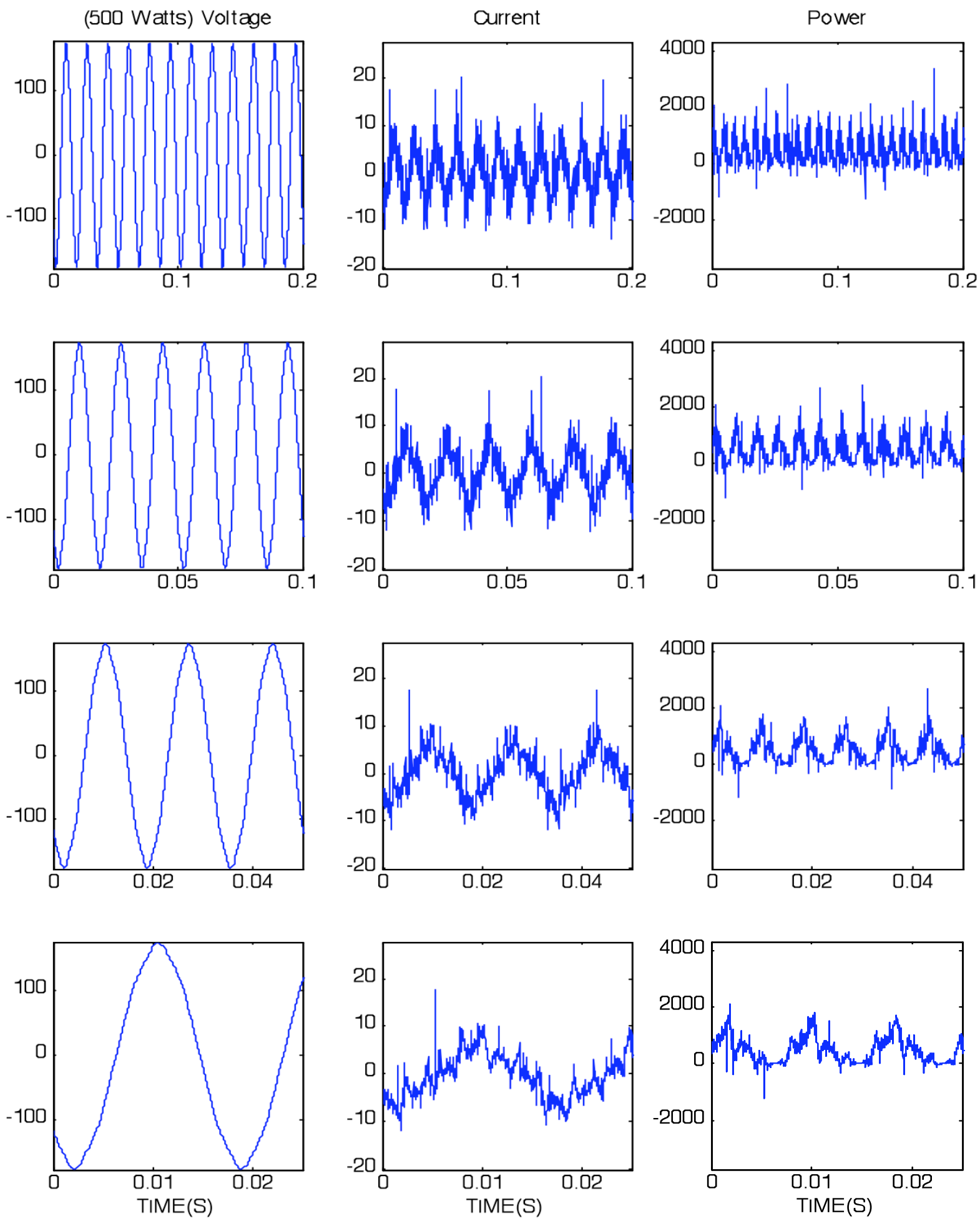

Figure 2: TQG electrical data for 500-watt load (voltage in left column, amperes in the center column, and watts in the right column) over various time scales that decrease from top to bottom to display the underlying structure. Note the classic sinusoidal variation in each signal, as well as the largeamplitude, nonlinear, complex "noise" component in the current and power. 

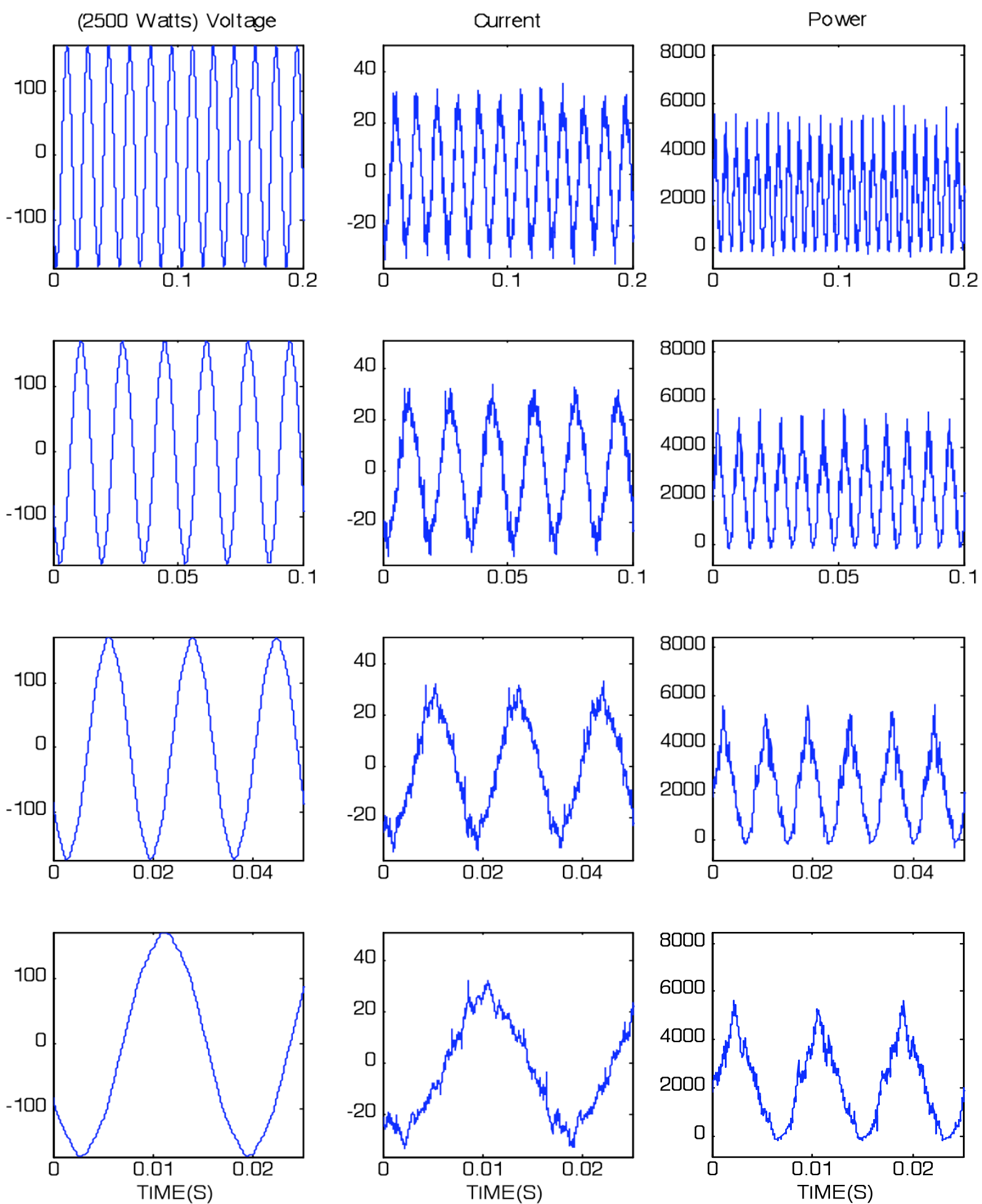

Figure 3: TQG electrical data for 2500-watt load (voltage in left column, amperes in the center column, and watts in the right column) over various time scales that decrease from top to bottom to display the underlying structure. Note the classic sinusoidal variation in each signal, as well as the modestamplitude, nonlinear, complex "noise" component in the current and power. 

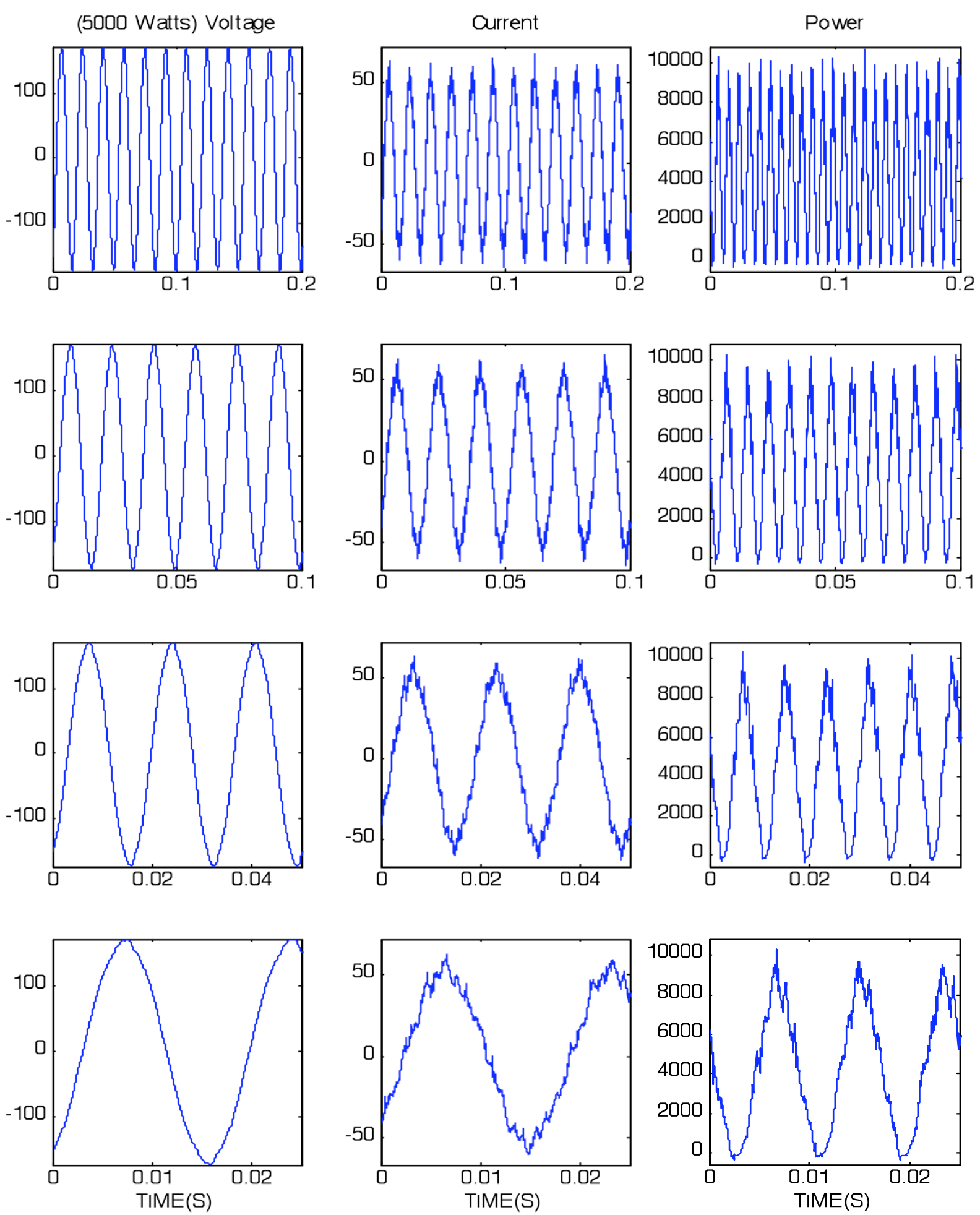

Figure 4: TQG electrical data for 5000-watt load (voltage in left column, amperes in the center column, and watts in the right column) over various time scales that decrease from top to bottom to display the underlying structure. Note the classic sinusoidal variation in each signal, as well as the smalleramplitude, nonlinear, complex "noise" component in the current and power. 

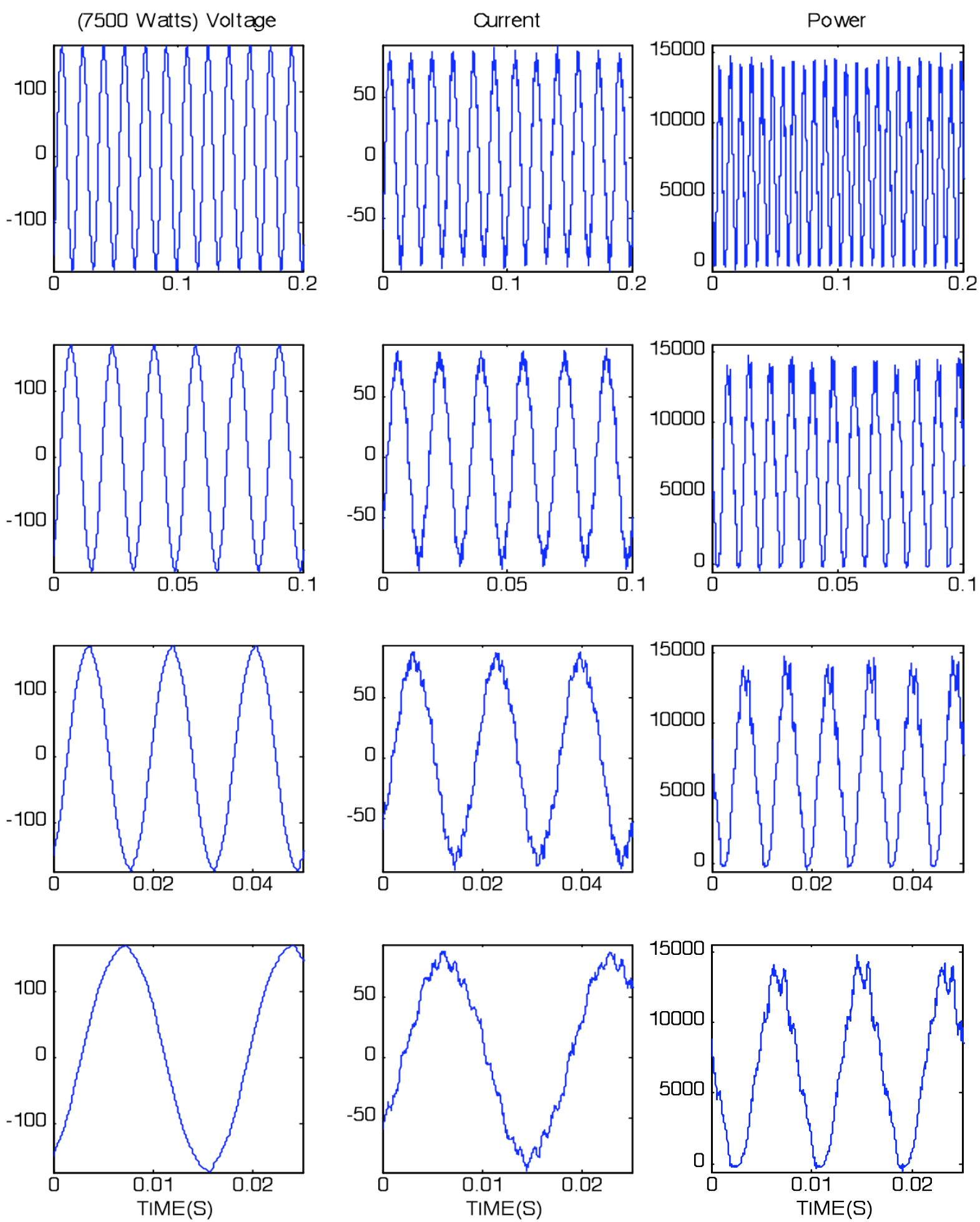

Figure 5: TQG electrical data for 7500-watt load (voltage in left column, amperes in the center column, and watts in the right column) over various time scales that decrease from top to bottom to display the underlying structure. Note the classic sinusoidal variation in each signal, as well as the smallamplitude, nonlinear, complex "noise" component in the current and power. 

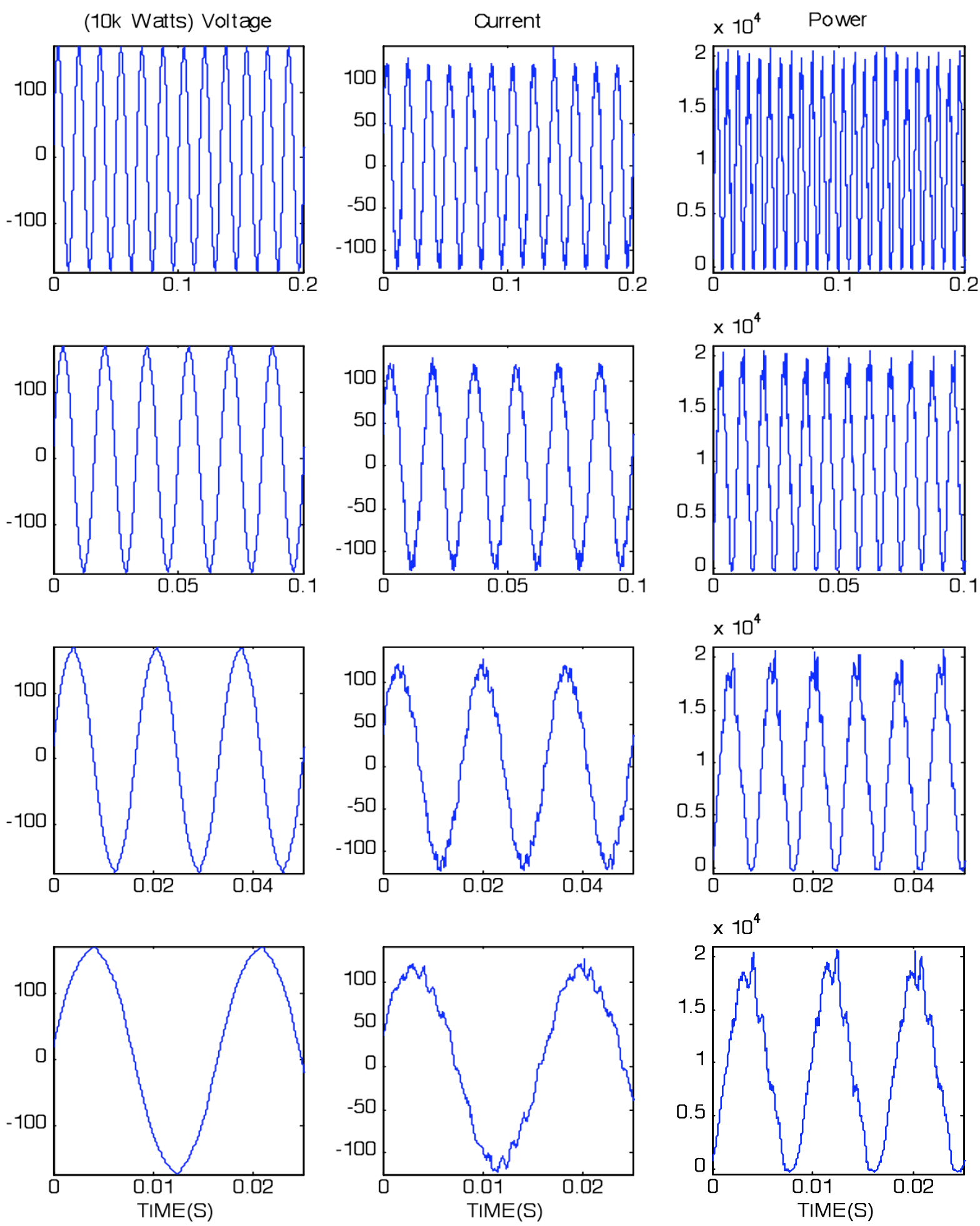

Figure 6: TQG electrical data for 10-kW load (voltage in left column, amperes in the center column, and watts in the right column) over various time scales that decrease from top to bottom to display the underlying structure. Note the classic sinusoidal variation in each signal, as well as the lowamplitude, nonlinear, complex "noise" component in the current and power. 
(00000 Watts) $A_{X}$
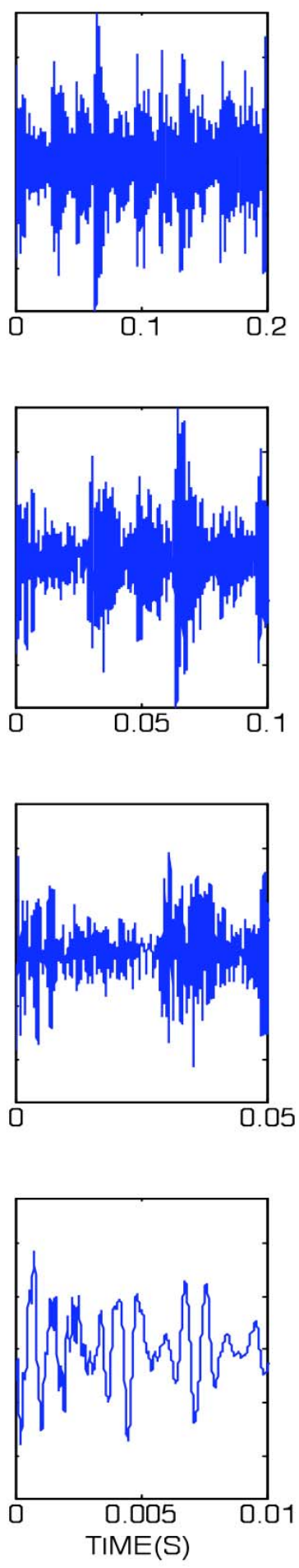
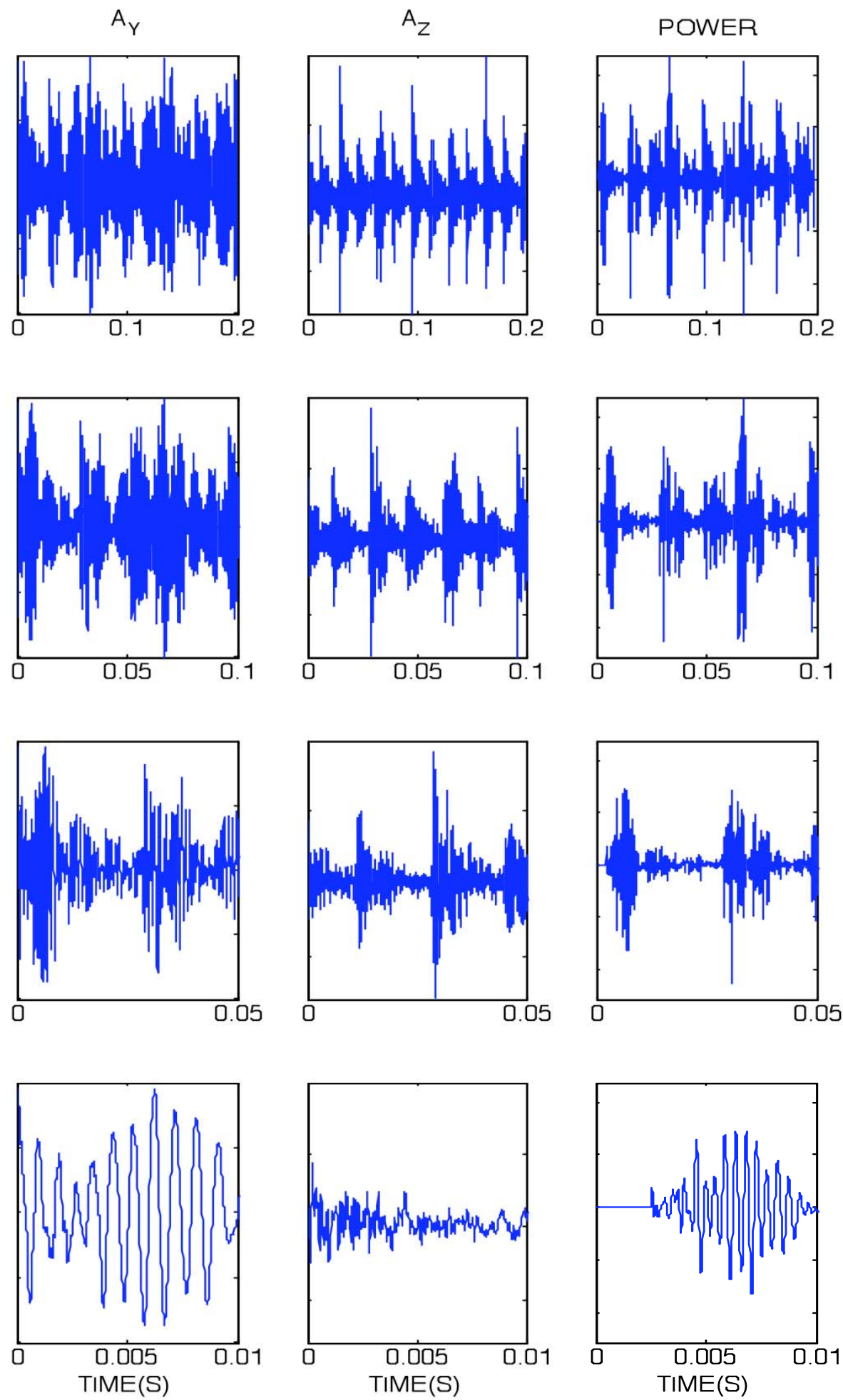

Figure 7: TQG acceleration no-load data (three orthogonal a-components in the left columns, and vibration power in the right column with all signals in the same arbitrary units) over various time scales that decrease from top to bottom to show the underlying structure. Note the complex, nonlinear features in all of the data channels. Acceleration data for other loads have very similar structure, and are not shown. 

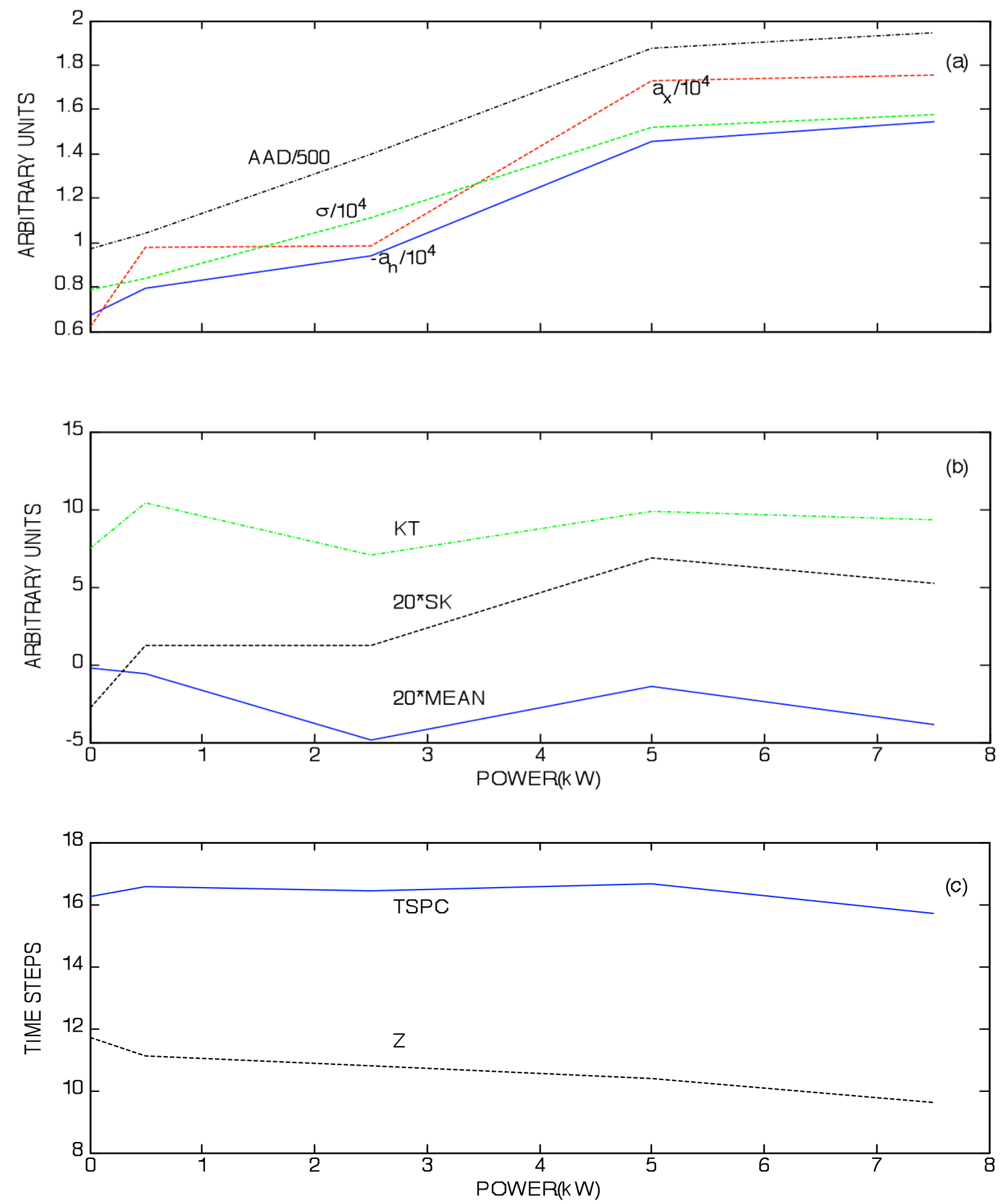

Figure 8: Various conventional statistical measures as a function of power-load on the TQG, showing: (a) absolute average deviation, AAD/500 (black -.-), standard deviation, $\sigma / 10^{4}$ (green --), minimum in the signal, $-a_{n} / 10^{4}$ (solid blue), and maximum in the signal, $a_{x} / 10^{4}$ (red --); (b) kurtosis, KT (green -.-), 20*skewness, SK (black --), and 20*mean (solid blue); and (c) time steps per cycle, TSPC (solid blue) and first zero in the auto-correlation function, $Z$ (black --). 

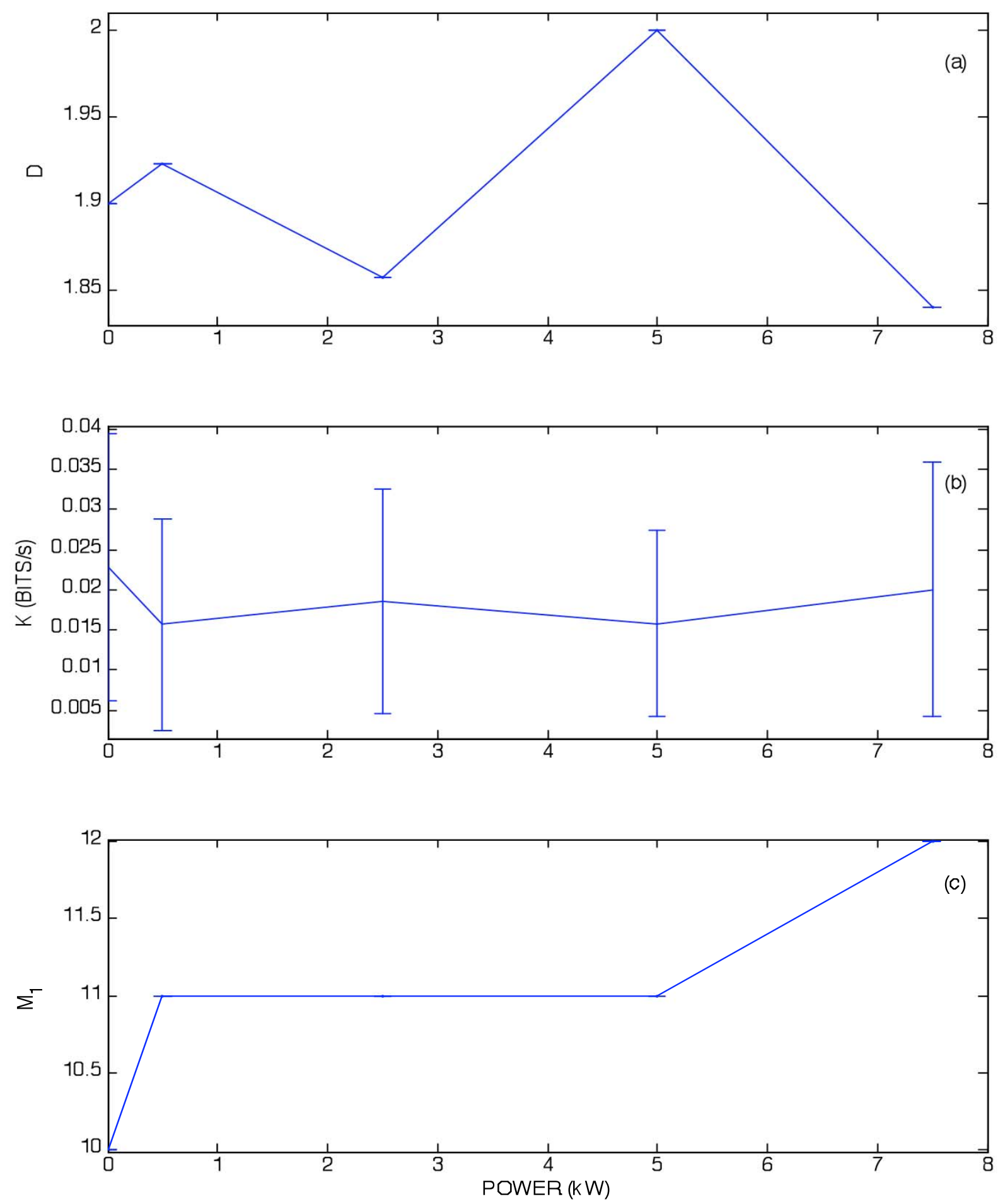

Figure 9: Error bars in each case correspond to one standard deviation. Note that the error bars in the correlation dimension (top plot) and first minimum in the mutual information function (bottom plot) are very small or zero, and consequently appear as a single horizontal line. 


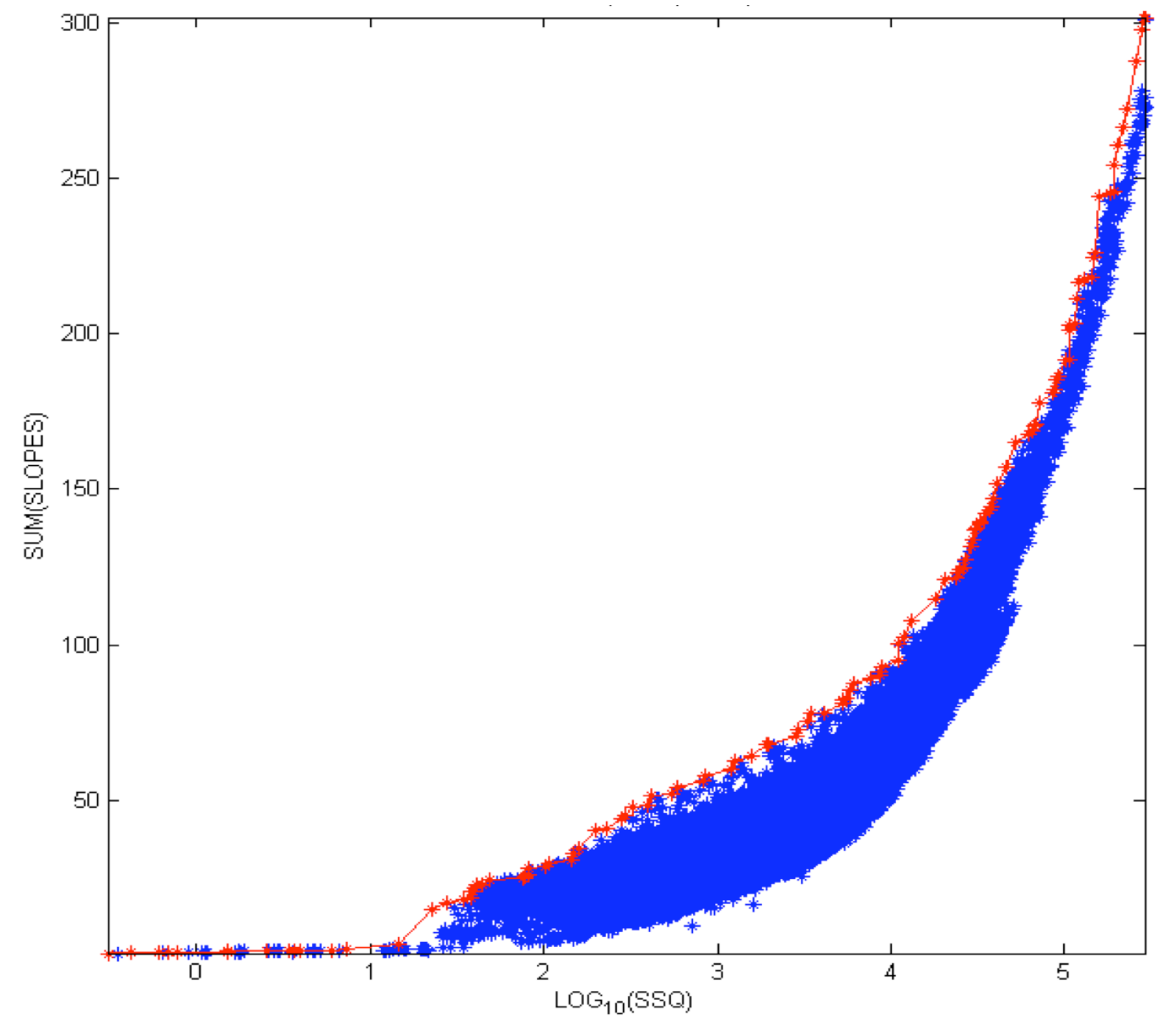

Figure 10: Sum of PSDM slopes versus least-sum-of-squares (SSQ) by a straight-line fit for an exhaustive search over $\mathbf{1 5 4 , 4 0 0}$ different parameter sets. This plot shows only 26,700 of those points, corresponding to proportionate change in the PSDM with TQG power. The best fits occur along the upper left boundary (corresponding to the largest slope for a specific value of the sum of squares), which is highlighted in red. See text for discussion. 

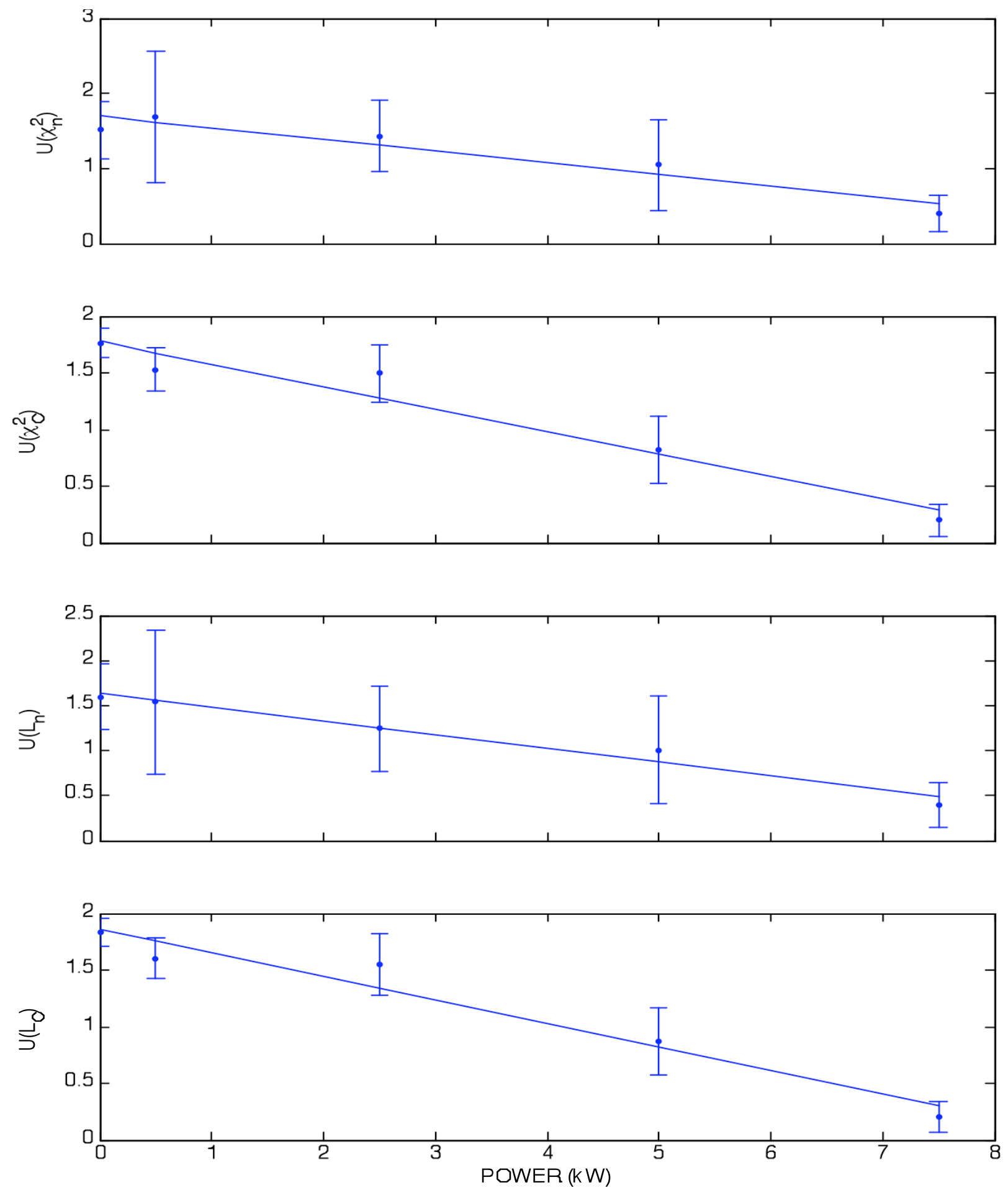

Figure 11: Plot of phase-space dissimilarity measures (and the associated error bars for one sample standard deviation) versus TQG power, where $7.5 \mathrm{~kW}$ corresponds to the baseline. The phase space parameters for this case are: $d=3, S=240, U E=1$ (equiprobable symbols), and $\mu=48$. 


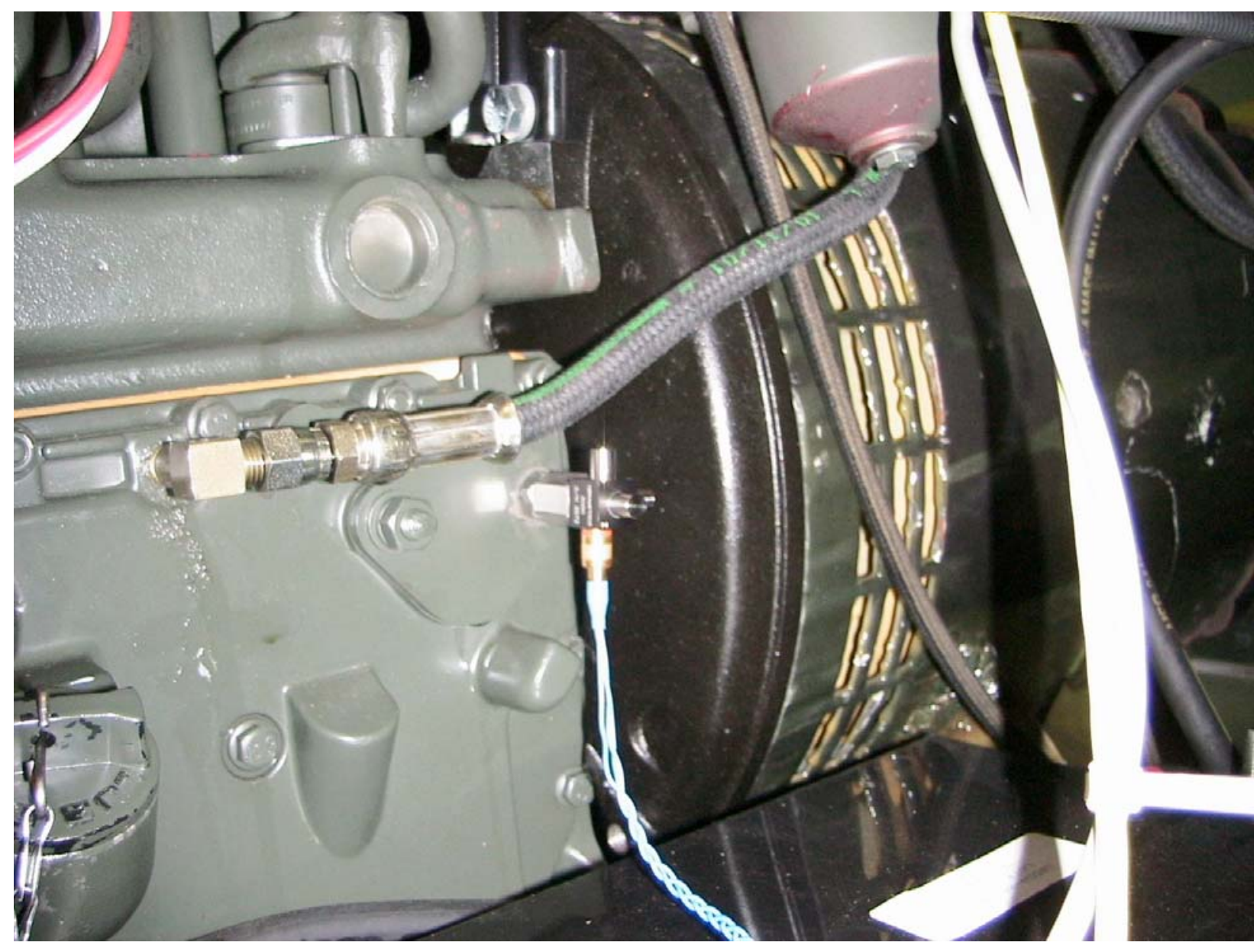

Figure 12: Picture of the U.S. Army's Tactical Quiet Generator (TQG), showing the accelerometer location on the engine block. Picture is courtesy of the U.S. Army Research Laboratory. 

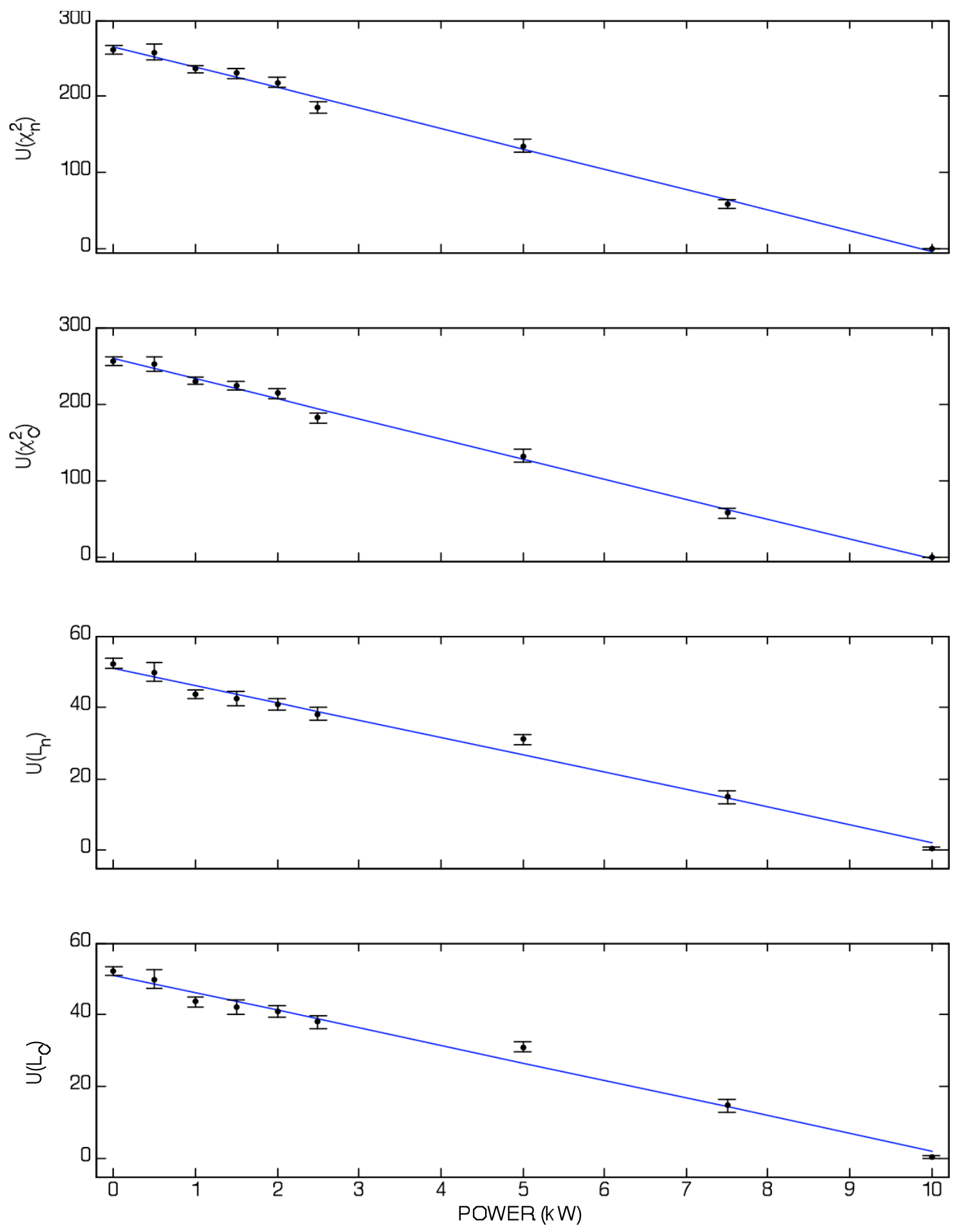

Figure 13: Plot of phase-space dissimilarity measures from the generator-enclosureaccelerometer data (and the associated error bars for one sample standard deviation) versus TQG power, where $10 \mathrm{~kW}$ corresponds to the baseline. The phase space parameters for this case are: $d=2, S=$ $4, \mu=81$, and $U E=0$ (uniform symbols). 

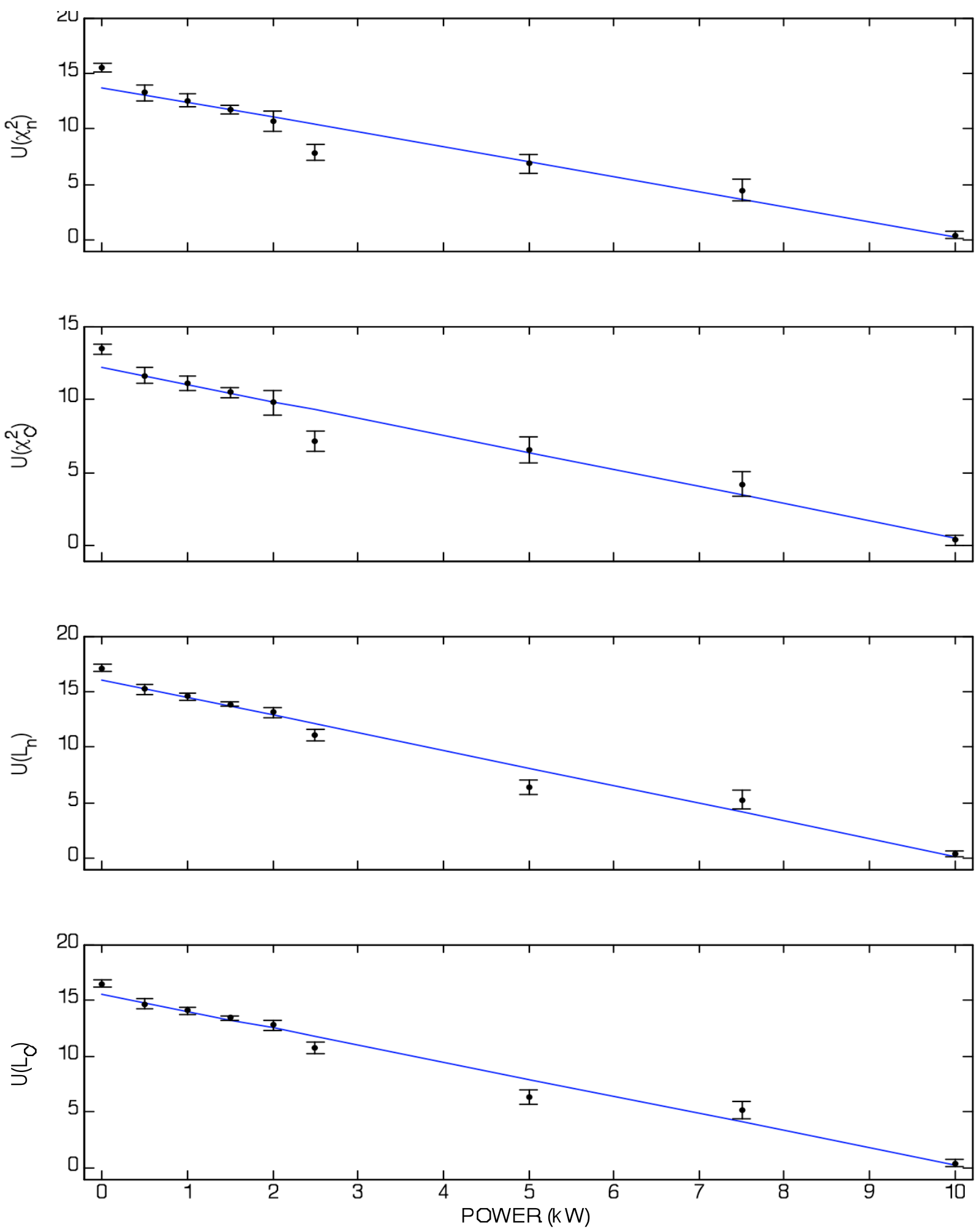

Figure 14: Plot of phase-space dissimilarity measures from the engine-block-accelerometer data (and the associated error bars for one sample standard deviation) versus TQG power, where $10 \mathrm{~kW}$ corresponds to the baseline. The phase space parameters for this case are: $d=9, S=5, \mu=50$, and $U E$ $=0$ (uniform symbols). Essentially the same result is obtained for $d=10, S=5, \mu=50$, and $U E=0$. 

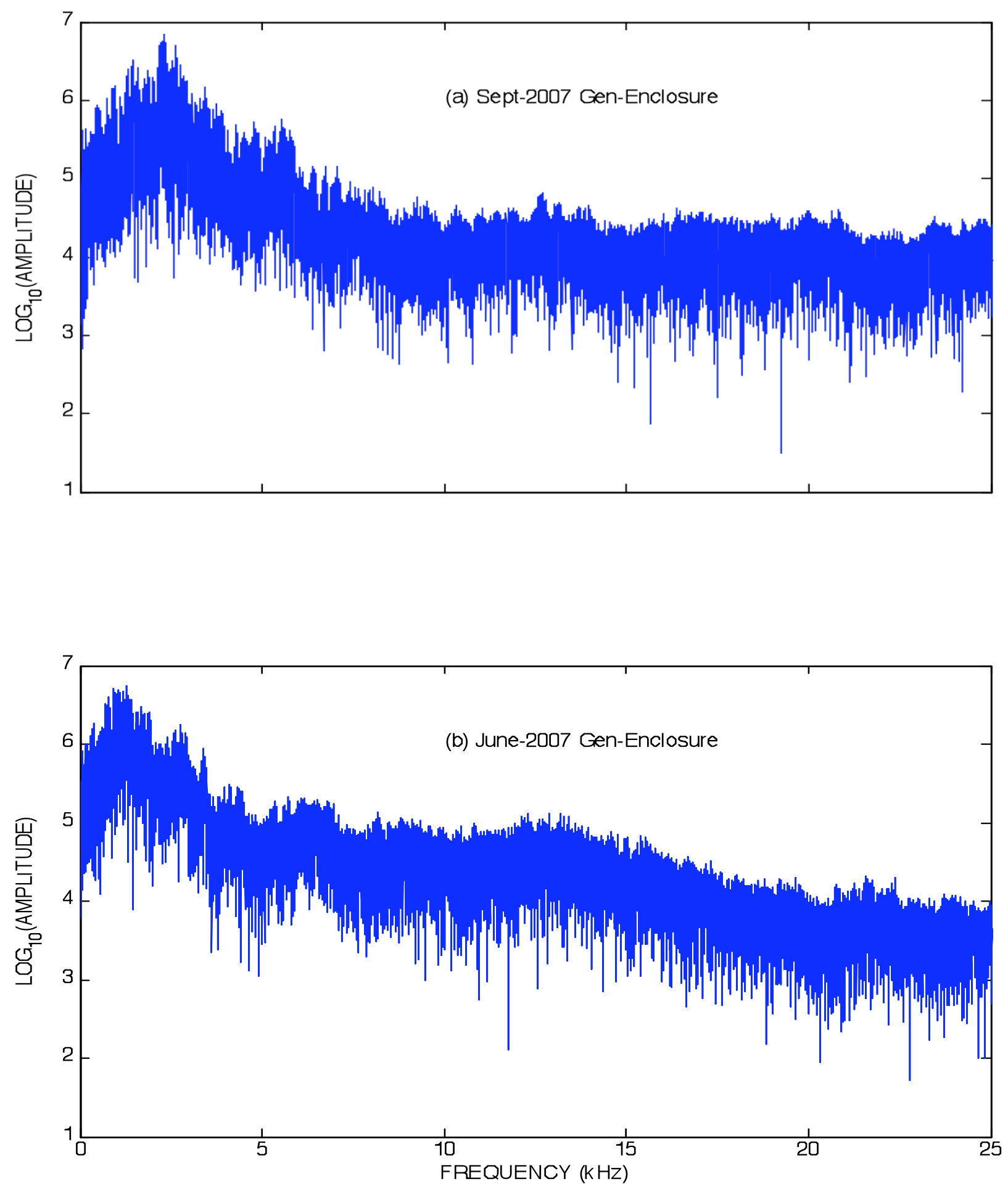

Figure 15: Fourier spectra of the generator-enclosure accelerometer power from (a) the September-2007 experiment with a 10-kW baseline, and (b) the June-2007 experiment with the 7.5-kW baseline. See the text for discussion. 

ORNL/TM-2008-012455

\section{INTERNAL DISTRIBUTION}

1. L. M. Hively

2. J. P. Trien

3. B. A. Worley

4. Central Research Library

5. ORNL Laboratory Records-RC

6. ORNL Laboratory Records-OSTI

\section{EXTERNAL DISTRIBUTION}

7. U.S. Army Research Laboratory, 2800 Powder Mill Road, Adelphi, Maryland, 20783-1197 Attention: AMSRD-ARL-SE-RU (A. Bayba) Attention: AMSRD-ARL-SE-RU (M. Conn) Attention: AMSRD-ARL-SE-RU (L. Currano) Attention: AMSRD-ARL-SE-RU (R. Del Rosario) Attention: AMSRD-ARL-SE-RU (H. Khatri) Attention: AMSRD-ARL-SE-RU (G. Mitchell) Attention: AMSRD-ARL-SE-RU (K. Ranney) Attention: AMSRD-ARL-SE-RU (S. Stratton) Attention: AMSRD-ARL-SE-RU (K. Tom) Attention: AMSRD-ARL-SE-RU (D. Washington)

8. U.S. Army Research Laboratory VTD, NASA Glenn Research Center, 21000 Brookpark Road, M.S.23-3, Cleveland, Ohio, 44135

Attention: T. Krantz Attention: D. Lewicki

9. Selma Matthews, Senior Research Scientist, CERDEC Command and Control Directorate, AMSRD-CER-C2-AP-PT, 10108 Gridley Road, Suite 1, Fort Belvoir, Virginia, 22060-5816 